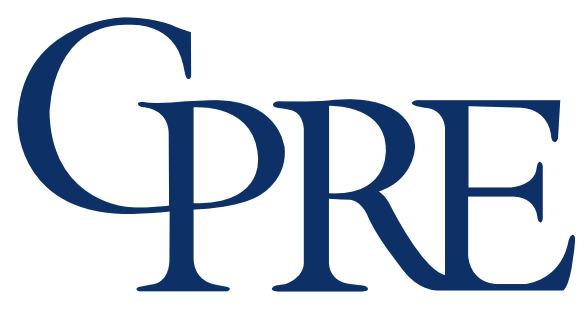

CONSORTIUMFOrPOLICY RESEARCHinEDUCATION

\title{
Strategies for \\ Strengthening the \\ Technical Workforce
}

A Review of International Evidence

Katharine Conn

Elizabeth Park

Wakasa Nagakura

Sherihan Khalil

Thomas Corcoran

TEACHERS COLLEGE COLUMBIA UNIVERSITY 


\section{Suggested Citation}

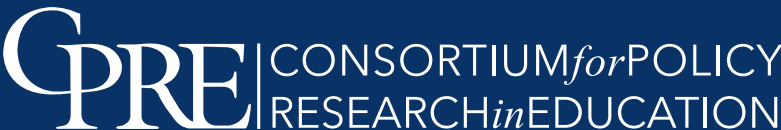

The Consortium for Policy Research in Education (CPRE) brings together education experts from renowned research institutions to contribute new knowledge that informs PK-16 education policy and practice. Our work is peer-reviewed and open-access at cpre.org. CPRE's member institutions are the University of Pennsylvania; Teachers College, Columbia University; Harvard University; Stanford University; University of Michigan; University of Wisconsin-Madison; and Northwestern University.

Consortium for Policy Research in Education |

PennGSE, University of Pennsylvania 3440 Market Street, Suite 560 | Philadelphia, PA $19104 \mid$ (215) 573.0700 | cpre.org
Conn, K., Park, E., Nagakura, W., Khalil, S., \& Corcoran, T. (2017). Strategies for Strengthening the Technical Workforce: A Review of International Evidence. Research Report (\#RR 2017-1). Consortium for Policy Research in Education, Teachers College, Columbia University.

Opinions expressed in this report are those of the authors and do not necessarily reflect the views of Teachers College-Columbia University, the Consortium for Policy Research in Education (CPRE), or its institutional members. The authors would like to thank Jonathan Supovitz, Benjamin Ogwo, Donna Murdoch, Sara Scovronick, and Amy Hawley for their helpful feedback and comments.

\section{Author Information}

Katharine M. Conn, PhD

Senior Research Scientist, Consortium for Policy Research in Education, Teachers College.

\section{kmc2169@tc.columbia.edu}

\section{Elizabeth H. Park}

Doctoral Candidate, Politics \& Education, Teachers College, Columbia University, and Research \& Evaluation Manager, New York City Department of Education.

ehp2112@tc.columbia.edu

\section{Wakasa Nagakura, PhD}

Senior Research Scientist, Consortium for Policy Research in Education, Teachers College.

\section{wn24@tc.columbia.edu}

\section{Sherihan Khalil}

Research Affiliate, Consortium for Policy Research

in Education, Teachers College, Columbia University, and Country Coordinator, DFID Girls Education Challenge, Afghanistan.

\section{Sherihan.khalil@shanglobe.com}

\section{Thomas Corcoran}

Co-Director, Consortium for Policy Research in Education, Teachers College, Columbia University. tbc2106@tc.columbia.edu 


\section{TEACHERS COLLEGE}

COLUMBIA UNIVERSITY

\section{Strategies for Strengthening the Technical Workforce}

A Review of International Evidence

Introduction

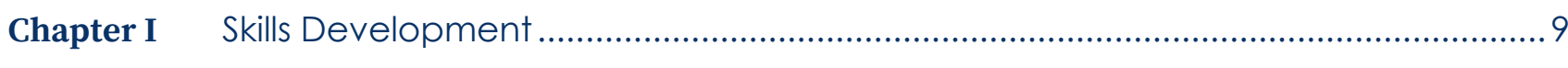

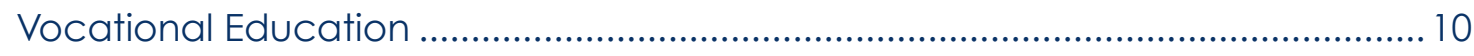

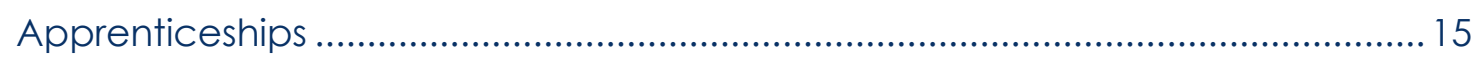

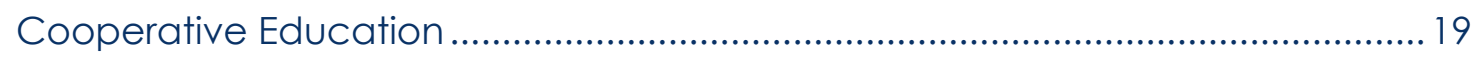

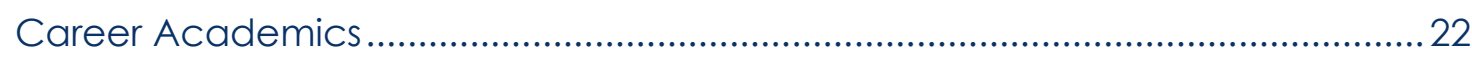

Workforce Training Through E-Learning ...................................................... 26

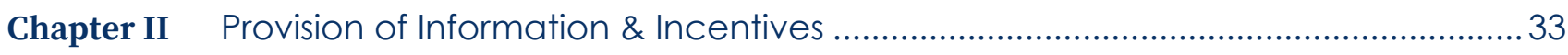

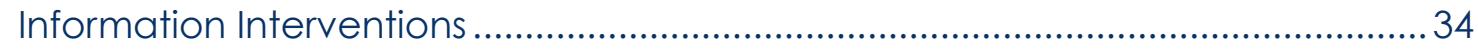

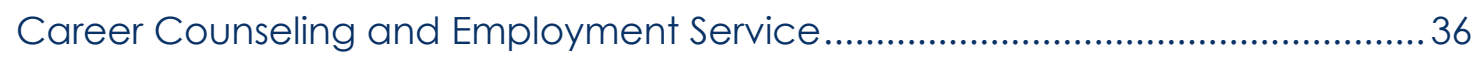

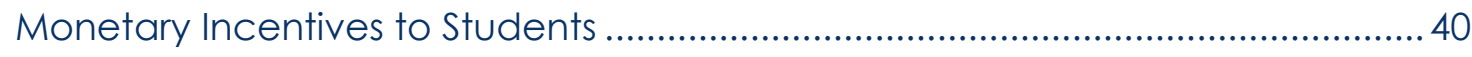

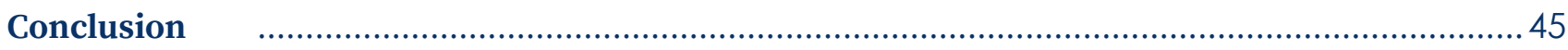

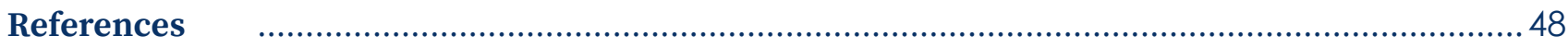

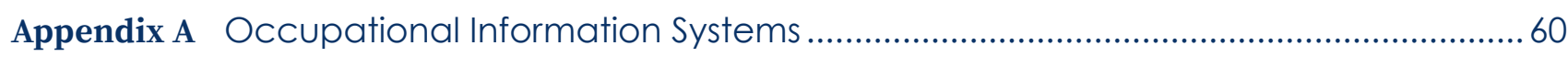

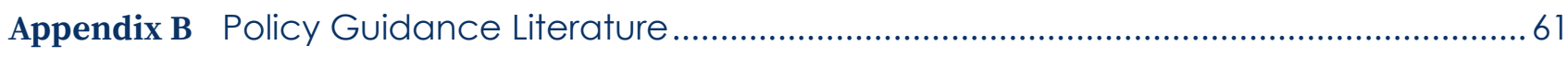

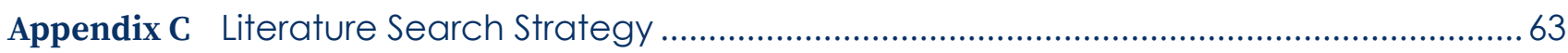




\section{Strategies for \\ Strengthening \\ the Technical \\ Workforce}

Katharine Conn

Elizabeth Park

Wakasa Nagakura

Sherihan Khalil

Thomas Corcoran 


\section{Introduction}

Numerous countries suffer from a shortage of technicians and skilled workers, particularly in the STEM fields (science, technology, engineering, and mathematics), due to a mismatch between the skills and interests of the students graduating from or leaving the current education system and the needs of the labor market. Often, parents and students place a high priority on entering and completing university, and as a consequence, many students pursue academic education in secondary schools in order to gain entrance to university, only to find themselves entering the job market lacking the skills they need for employment and advancement. Further, in some countries, the vocational school system is not well-respected by the public and focuses heavily on preparation of youth for specific jobs in one firm rather than preparing them for careers within an industry as a whole. This literature review aims to synthesize the research evidence about the effectiveness of various strategies used by national governments, non-governmental organizations, technical schools, and industries to strengthen both the quality of the technical workforce, as well as the avenues through which individuals can access career and technical programming.

To help policymakers develop strategies to meet these challenges, we examine research findings in two broad solution domains making up the two major chapters of this review: Chapter I. Skills Development and Chapter II. Provision of Information \& Incentives. Within each domain, multiple strategies have been identified that address these workforce development issues by providing opportunities for different population groups. While Chapter I focuses on strengthening skills development through various types of career and technical education, Chapter II highlights strategies to increase access to this type of programming. This reviews aims to be international in nature, though some workforce development strategies (and thus research on these strategies) tend to be region-specific. For example, while vocational education research has been conducted worldwide, apprenticeship research is largely limited to Europe, and cooperative education as well as career academy research is limited to North America.

The five primary strategies assessed in the first chapter of this review include various types of career and technical education: vocational education, apprenticeships, 
cooperative education, career academies, and e-learning programs for the workforce. While vocational education programs, apprenticeships, and e-learning programs exist both within and outside of the formal education system, cooperative education programs and career academies exist largely within the education system. As most programs under study are relatively small and region-specific, the effectiveness of these strategies is assessed in terms of individual-level outcomes including academic outcomes (performance, retention, completion, etc.), as well as labor market outcomes (employment status, wages, length of employment search, etc.), though studies on vocational education and apprenticeship strategies do include macro-economic-level outcomes such as country-level employment rates, job turnover, or labor market productivity. These five strategies are summarized below:

Vocational education aims to impart students with a certain type of knowledge, understanding, and competencies that are necessary for future work within a particular industry or occupational field. Its occupation-specific curriculum prepares students for a specific trade, craft, or career by directly developing essential expertise, applicable techniques, and skills for employment, often through the use of a work-based learning. Vocational education can be offered within the formal education system as well as outside of the system (e.g., labor market training programs).

Bridging the gap between theory and practice, apprenticeships provide individuals with an opportunity to gain a mix of classroom or workshop instruction and on-the-job training. During the course of between three to six years (depending on the program), apprentices gain real life experience by working under the supervision of an advanced professional.

Similarly, cooperative education ("coop") is another method of combining classroom-based education with practical work experience. Coop education is a type of internship program that enables students to receive career training (typically with pay) for academic credit. Coop programs provide individuals with an opportunity to explore career choices and to network with professionals.

Additionally, career academies are formal, high school based small learning communities organized around such themes as health sciences, law, engineering, and business and finance. In academies, students receive academic instruction at their theme-focused high school combined with work-based learning opportunities at an industry center, or technical school or college.
Lastly, e-learning programs involve the use of a wide variety of applications and processes such as computer or electronic technologies to deliver a broad range of educational curricula; these programs can target both students as well as individuals already in the workforce. Potential benefits of e-learning include its ability to provide distance learning (as opposed to learning on a campus); to provide a blended classroom approach (combination of face-to-face and technology-based teaching and learning); and to provide an additional avenue with which to support teaching and learning practice.

In addition to improving the skills of the workforce, providing access to information and employment services in the technology field, as well as monetary incentives to students to enter into these fields can have a large impact on individual choice and subsequently overall access to career and technical programming. The provision of information and incentives includes three primary strategies: informational interventions to potential students, strengthening of both informal and formal career counseling and employment services, and monetary incentives for students. The effectiveness of these programs is generally assessed through outcomes such as increased enrollment in a particular school or field, academic performance in the program of choice, as well as various labor market outcomes of those taking part in these initiatives. A brief summary of each type of strategy is detailed below:

- Concerns about the low visibility and take-up rates of government supported workforce development programs have prompted calls to provide more information interventions. Information interventions include efforts to reach out to students and families to educate them about the availability of program, the financial returns or the benefits of a certain type or level of education, their post-secondary aid eligibility, and school performance rankings. Information interventions can also include efforts to simplify or to provide greater assistance with the application process.

- With more and more diverse career options and professional opportunities emerging, career counseling and employment services help individuals make the right choice about their career paths, career development, and career change. Career counseling involves the counseling or mentoring/coaching of individuals (adults as well as adolescents or students) to help them make informed career choices and define their career paths. This type of counseling can be offered formally through schools or other government institutions, as well as through informal or private channels. In addition, employment services are agencies that attempt to match the employment 
needs of an employer with an individual who obtains the required skillset and interests.

- Monetary incentives are financial rewards given to employees or students to motivate participation or performance. With respect to education, monetary incentive structures (scholarships, vouchers, stipends, etc.) are offered to students to encourage enrollment, attendance, and completion; reduce dropout rates; and to improve learning outcomes and post-secondary school aspirations.

These three approaches to tackling the shortage of technicians and skilled workers apply not only to an immediate plan to recruit employees, but also to a long-term plan to build and retain a technical workforce for the future.

Our methodological approach to this review was systematic; that is, we attempted to examine all of the relevant and rigorous empirical research in each of the solution domains, following the Cochrane Handbook for Systematic Reviews of Interventions (Higgins \& Green, 2011). The inclusion criteria for the review focused on the two main solution domains as well as the rigor of the methodology used. Preference was given to efficacy trials that used experimental methods (randomized controlled trials) or quasi-experimental methods (propensity score matching, instrumental variables, regression discontinuity designs, differencein-difference designs, natural experiments, time series analysis, etc.). This is due to the fact that these methods allow for a causal interpretation of the impact of each program; that is, the impacts measured are fully attributable to the program or policy itself and not to other confounding factors such as student background variables or the presence of other concurrent policies or economic factors. However, while these studies have high internal validity (lack of bias) in their impact estimates, their external validity (the extent to which their findings can be extrapolated to other contexts) must be determined case by case. In addition, certain high-quality correlational, descriptive, and observational studies were included when highly relevant, and in some cases policy reports and case studies were used to add another perspective to the evidence. Note that in addition to the efficacy literature upon which the bulk of this paper is based, Appendix B provides an overview of relevant and recent policy-relevant reports, manuals, and books which were identified through our systematic search.

While the search criteria and search terms differed slightly by topic, the studies included in this review were located in three main ways: (1) searches of the following databases: Education Research Complete, Business Source Complete, ERIC, Education Full Text, Social Sciences Full Text, and EconLit with Full Text, as well as Google Scholar; (2) searches of online impact evaluation databases such as the International Initiative for Impact Evaluation (3ie) Database, ' the World Bank Education Database, ${ }^{2}$ and the Youth Employment Inventory; 3 (3) searches of relevant international organization websites, including the World Bank, UNESCO, OECD, IZA, and ILO; and (4) "citation crawling" of relevant meta-analyses and other wellcited studies within each field. Appendix C provides a detailed description of the search strategy used including search terms for each topic.

Analytically, this review attempts to synthesize the literature in such a way that broad patterns in program outcomes can be identified, and to the extent that the findings of program effects are conflicting, we have attempted to explain and learn from this variation. Note that this review does not pool effect sizes as in a meta-analysis, as the outcomes across these interventions differed too greatly to be combined into one average measure (i.e., the effects of vocational programs were measured in a variety of ways including starting salaries, current wages, hours worked, time to employment, employment status, formality of employment, and educational outcomes (in vocational school) including academic performance, retention, and completion).

For each strategy examined below, we provide a description of the literature (the population samples targeted, the publication types within the literature, the outcomes examined across studies, methodologies used, and geographic distribution of the studies); a summary of the findings; and a brief description of the limitations and implications of the synthesis. This review is structured as follows: Chapter I. Skills Development, details the evidence on the effectiveness of various types of career and technical education to improve the quality of technical education (this includes vocational education and training, apprenticeship trainings, cooperative education, career academies, and workforce training through e-learning), while Chapter II. Provision of Information \& Incentives, speaks to the impact of informational interventions, career counseling and employment services, and monetary incentives in strengthening access to technical education.

\footnotetext{
$1 \mathrm{http}: / / \mathrm{www} .3$ ieimpact.org/evidence/

$2 \mathrm{http}: / /$ datatopics.worldbank.org/EdStatsApps/Edu\%20Evaluation/evaluationHome.aspx?sD=E

$3 \mathrm{http}: / /$ www.youth-employment-inventory.org/
} 
Strategies for

Strengthening

the Technical

Workforce 


\section{Skills}

\section{Development}

This chapter addresses the "Skills Development" solution domain and includes five main strategies for strengthening the career and technical education sector and addressing skills shortages: vocational education (formal and non-formal), apprenticeships, cooperative education, career academies, and e-learning programs for the workforce. The section on vocational education below details the importance of links to industries and the quality of vocational training, discusses the macro and micro implications of interventions in this field, describes the differential effects of programs by gender, and addresses returns to public versus private sector vocational programming. Secondly, the research on apprenticeship programs included in this review addresses an array of topics including the country-level factors influencing apprenticeship provision, how apprenticeships impact wages, transition to employment and length of employment, the effect of apprenticeships on the macro economy, and heterogeneous effects associated with apprenticeships.

Overall, the studies on cooperative education at the secondary and post-secondary level examine the effect of coop education on completion and retention rates (for both school and work-related outcomes), as well as the psychological impact of taking part in a cooperative program. Efficacy literature on career academies explore their impact on secondary school outcomes, post-secondary school outcomes, and labor market outcomes. Finally, the e-learning studies included in this section explore the lack of significant achievement differences between e-learning and none-learning programs and the heterogeneity that exists within these findings. The efficacy literature for each of these five approaches is synthesized in greater detail below. 


\section{Vocational Education}

\section{Katharine Conn}

Vocational education refers to education or training which is focused on preparation for work in a particular industry or field and is often accredited or regulated at either the regional or national level. Vocational education can be offered both within and outside of the education system. Formal vocational education programs are a common form of secondary or post-secondary education in many countries and are often offered within universities, community colleges, institutes of technology, or other registered training organizations. These programs often have a work-based learning component. Further, non-formal vocational education programs are also very common worldwide as a form of "workforce retraining." In some countries the vocational sector interacts with established apprenticeship programs (discussed in the following section). In this section we describe what is known from the research literature regarding the efficacy of vocational education programs. This section includes a description of the literature as a whole (program population targets, publication types, outcomes, methodologies, regions covered, etc.), the relevant findings associated with this body of work, and any limitations or implications of these studies.

\section{Literature Description}

Thirty-six studies of the impact of vocational education on youth were identified for inclusion in this synthesis. ${ }^{4}$ The following section provides an overview of the characteristics of the studies found through the systematic review process and which are included in this synthesis.

Study Population. Of the 36 high-quality vocational education studies identified for this synthesis, only one of them examined an intervention targeted at students currently in school [Bettinger, Kremer, and Saavedra (2010) focused on Kenyan 5th grade students as they chose between the general or a pre-vocational track]; the majority of the remaining interventions targeted unemployed or low-income youth under 30 .

Publication Type. Of the 36 high-quality vocational education studies identified for this synthesis, 15 are journal articles, 3 are reports, and the remaining 19 are working papers.

Outcomes. Most of the outcomes examined in the vocational education literature focused on the individual returns to vocational schooling (wages, hours worked, employment status, formality of employment, academic performance, retention, and completion rates). Only one study (Dmitrijeva, 2009) examined the impact of a vocational program on macroeconomic indicators (aggregate outflows from unemployment to jobs). This is largely due to the fact that these programs were often too small for researchers to expect a general equilibrium effect.

Methodology. Of these vocational education-related studies, 10 employed randomized controlled trials, 18 employed some form of matching (namely propensity score matching), 2 employed instrumental variables, 1 used a natural experiment, 2 employed Heckman selection correction, ${ }^{5} 1$ used a regression discontinuity design, 1 involved a bivariate duration model, and 1 employed multiple strategies (randomized controlled trial as well as matching).

Region. With regard to geographic location, the efficacy studies in this sample are from multiple continents: three studies in Africa (Kenya, Liberia, and Kenya \& Zambia); four in Asia (Bhutan, Thailand, and two in China); five in Central America and the Caribbean (Panama, two in the Dominican Republic, and two in Mexico); nine in South America (two in Peru, three in Argentina, three in Colombia, and one that is pan-Latin American); eight in Eastern Europe/ Western Asia (Slovenia, Bulgaria, Latvia, Romania, two in Russia, and two in Turkey); five in Western Europe/ Nordic countries (Finland, two in Sweden, and two in Norway); and two in North America (United States). No studies meeting the criteria were found in countries with strong reputations for providing effective vocational education such as Germany, Singapore, and Taiwan.

Training field. The majority of these impact evaluations did not report detailed information as to the type of vocational education offered. Eight studies reported that the intervention placed students with "firms," but did not state exactly what kind of firms or skills the students gained. One evaluation (Alzúa, Nahirñak, \& Alvarez de Toledo, 2007) of an Argentine program "Entra 21 " described in detail the kind of ICT training its students received. Jóvenes en Acción in Colombia (Attanasio, Kugler, \& Meghir, 2011 ) provided training in multiple fields: administrative occupations, manual occupations, and skilled occupations (IT specialists, data entry, surveyors, and accountant assistants). A "laid-off" worker re-training program in China provided IT and services training. A rural skills development program in Bhutan (Chun \& Watanabe 2011) provided

4 See Appendix C for a description of the search strategy and search terms.

5 Heckman correction is not a quasi-experimental strategy, but it uses two-stage estimation method to correct for selection bias. 
specific construction skills to participants (carpentry, masonry, plumbing, and electrical wiring). And Bettinger, Kremer, and Saavedra (2010) evaluated a vocational education program in the services and manufacturing sector in Colombia.

Training length/type. The vast majority of programs evaluated in this literature were active labor market training (non-formal education) programs (32 studies), followed by evaluations of formal vocational education programs (4 studies), and finally, there was one program that examined the impact of vocational training for current employees. The modal length of the training programs in this synthesis was approximately 6 months (the range is from 3 months to 2 years). All of the vocational education interventions evaluated here offered students on-site training or workplace internships. Approximately $75 \%$ of these programs split the student's time between coursework and on-the-job training. The remaining $25 \%$ offered exclusively on-thejob training.

\section{Findings}

The findings from this review detail both the effectiveness of these programs in improving participant outcomes, as well as the conditions under which vocational education programs are most successful. The findings emphasize the importance of links to industries and the quality of training; discuss the macro and micro findings of these studies; describe the differential effects of programs by gender; and address returns to public versus private sector vocational programming.

Links to industries. There is suggestive evidence that interventions which link vocational education and training most closely to targeted industries tend to be the most successful in terms of student outcomes. Programs in which the student receives a paid internship are particularly useful in that the employer can use the internship as a screening process for hiring (given that they have already invested in the training of the individual). If students' wages are not paid by the firm, however, this can create perverse incentives. To this point, Card, Ibarraran, Regalia, Rosas, and Soares (2011), in an evaluation of a youth training program in the Dominican Republic, found that because the interns' wage costs were fully subsidized by the program, employers had a strong incentive to fill their slots with new trainees once the subsidy period came to an end rather than to hire graduates from the program. Further, Chun and Watanabe (2011) studied a rural skills development program in Bhutan that provided training to participants in carpentry, masonry, plumbing, and electrical wiring.
But because this training was not linked to an industry or firm, the employment benefits were lower than expected, causing the authors to conclude that there is a need for "a greater emphasis on creating a mechanism to connect the training program to income generating opportunities via job placement services, entrepreneurship, or mentoring services-especially in competitive labor markets where there are too many trainees in relation to the population" (p. v).

Innovations in the way in which industries can be linked to vocational training programs include an implementing organization that also functions as a placement office for the unemployed, as in the case of the Probecat training program in Mexico. In this case, post-training, $70 \%$ of the trainees were hired by the firm with which they were interning; the remaining students then tried to find a position through the SNE (Sistema Nacional de Empleo) placement office (Delajara, Freije, \& Soloaga, 2006). Another example is the program Entra 21 in Argentina, which required the implementing NGO to commit to inserting $40 \%$ of their graduates in the labor market (Alzúa et al., 2007).

Quality of training. Chong and Galdo (2006) found in their study of a youth training program in Peru (PROJOVEN) that the quality of the training program was highly correlated with student success. They found that the quality premium was over 20 percentage points (in wages) between individuals who attended high- and low-quality courses. In their measure of quality, they included six different categories: class size, expenditures per trainee, eight teacher variables, six infrastructure and equipment physical characteristics, nineteen curricular structure variables, and nine variables characterizing the link between the content of the training courses and the institution's knowledge about workers and occupational analysis of labor demand.

To ensure the participation of high quality training programs, the selection of training institutions is often based on a public bidding process that can include various eligibility criteria: legal status (formality) and the existence of some acceptable level of human resources and infrastructure (PROJOVEN in Peru, Chong \& Galdo, 2006); legal registration, economic solvency, quality of teaching, and ability to place trainees after the classroom phase into internships with registered employers (Jóvenes en Acción in Colombia, Attanasio et al., 2011); and existence of a written commitment by private firms to provide paid internships, past training experience, administrative capacity, and the adequacy of the courses provided (Projoven in Peru, Díaz, \& Jaramillo, 2006). 
Macro findings. Only one quasi-experimental study examined the impact of a vocational education program on outcomes beyond the individual; Dmitrijeva (2009) found that the effects of publically provided training programs (namely vocational education) for the unemployed in Latvia (part of the government's Active Labor Market Policy) on outflows from unemployment to employment was positive and statistically significant. Further, the cost-benefit analysis findings held that the costs of training were easily covered at the aggregate level if the average job tenure in the economy approached nine months.

Micro findings. Again, the vast majority of programs evaluated in this literature were active labor market training (non-formal) programs (32 studies), followed by evaluations of formal vocational education programs (4 studies), and a program which examined the impact of vocational training for current employees (1 study). Overall, results in terms of individual employment, earnings, job formality, and other outcomes were mixed. Of the 32 studies examining the impact of public vocational training on these individual outcomes, the majority of these studies evidenced either null or statistically insignificant (though slightly positive) results (20 studies); the remaining studies had either positive (6 studies) or mixed results (6 studies). Studies with mixed results included those that were positive for employment but negative for wages or they were positive for only certain subgroups within the larger sample (by age, gender etc.). Further, there were unfortunately no clear patterns in the data that indicated the presence of an intervention-specific moderator. For example, there were no obvious patterns between particular program components or program length and resulting labor market outcomes. Thus, while these results varied due to the implementation quality of the interventions themselves, they were also likely to vary due to the economic context of each country or region. Betcherman, Dar, Luinstra, and Ogawa (2000) in a synthesis of active labor market training programs found the effectiveness of programs to be heavily reliant on the business cycle and to be much more successful in times of economic expansion. Additional moderating variables could include market saturation of certain skilled workers, unemployment rates, or the size of the skill-gap, etc. For example, in Alzúa et al. (2007), the vocational program implemented was identical (in principle) across countries, but the results differed wildly between Argentina and Brazil. In Argentina, there was a positive but insignificant effect on employment, a positive impact on income (though this decreased over time), and no statistically significant effect on formality, while in Brazil the program had no significant impact on either employment or earnings. One pattern in the data that does clearly emerge, however, is the strong impact of these programs on females (discussed in the next section).

Unlike the programs discussed above in which vocational trainings were offered to the unemployed workforce, a second set of studies evaluated the effects of attending a vocational school. Compared to traditional schooling, Loyalka et al. (2013c) and Rozelle et al. (2015) found negative effects of vocational schooling in China, while Moenjak and Worswick (2003) found positive effects in Thailand, though the latter analysis is largely correlational (with selection bias corrections). More specifically, Loyalka et al. (2013c), using matching and instrumental variables analyses with a sample size of 10,000 students in China, found that attending vocational school (instead of a traditional high school) reduced general skills and had no effect on specific IT skills. They further found that low-ability and low-income students were more likely to drop out of vocational programs, as compared to academic programs. Similarly, Rozelle et al. (2015) found negative effects of vocational education in comparison to traditional high schools. Using the expansion of vocational education in China as a natural experiment, they employed a differencein-difference approach to capture the returns of vocational schooling (versus regular schooling) on employment outcomes such as wages. They found that vocational education had inferior returns compared to general high schools.

Further, two studies examined the impact of "winning" a voucher to attend a vocational school (versus losing the lottery) and found that while these programs seemed to have an impact on educational attainment, the impact on earnings was less clear (or unmeasured). First, Bettinger et al. (2010) conducted a randomized experiment in Colombia and found that among 5th grade students who applied to receive a vocational education voucher, those that won the lottery and thus had their pick of both private and public sector vocational schools were more likely to complete more years of schooling, less likely to repeat grades, 56 percentage points more likely to take the ICFES examination (university entrance examination), and more likely to have a higher reading score than students that lost the vocational education voucher lottery. The authors hypothesized that this was due to the fact that voucher winners were more likely to find a better match to their interest area given that they had their pick of all private sector vocational opportunities, whereas those that lost the lottery were more likely to attend public vocational schools or regular academic schools. The authors argued that voucher winners may have performed better due to the fact that the 
provision of the voucher (year to year) was dependent on student performance or because these private organizations may be better able to adapt their offerings to the demands of the labor market (in this case the growing service sector).

In addition, Hicks, Kremer, Mbiti, and Miguel (2011) conducted a randomized experiment in which applicants to a technical and vocational vouchers program in Kenya were grouped into one control sample (half of the applicants) and two treatment samples (public school vouchers and private school vouchers, each representing one-fourth of the total students). They also randomly exposed half of treatment and control individuals to information about the actual returns to vocational education. In their preliminary analysis, the authors found that voucher winners were statistically more likely to enroll in vocational education and more likely to stay enrolled (with higher retention rates) than those awarded a restricted (public institution only) voucher. Further, among program completers, there is early, suggestive (but not statistically significant) evidence of earnings advantages for women but no overall impact on employment rates thus far.

The only study that examined the impact of a vocational training on current employees found positive effects of these trainings on wage earnings. Specifically, Rosholm, Nielson, and Dabalen (2007) conducted a quasi-experimental evaluation (using a "matching" methodology) of on-the-job training within formal sector enterprises (a sample of manufacturing firms) in Kenya and Zambia. The authors found a positive rate of return to these trainings of approximately $20 \%$; the effect was larger and more precisely measured for trainings done in larger firms and for trainings of longer duration. Further, the wage returns were larger for formal than for informal training in Kenya, while in Zambia, the reverse was true. However, there were some differences in background characteristics across control and treatment groups post-matching, thus the extent to which this estimated impact is purely causal comes into question. Also, the authors note the possibility that the training received by employees was concentrated among the most highly skilled, thus these results may not extrapolate to the workforce population as a whole. And finally, the authors estimated the effect of these trainings on those trained (a "treatment on the treated" effect), thus the average treatment effect would be expected to be smaller.

Differential impact by gender. While the studies included here offer mixed findings overall, one pattern did emerge across all contexts, and that was that women seemed to benefit more from these vocational education programs than men. While women may have been more reluctant to participate in vocational education programs (Hicks et al. 2011), their return on investment was often higher. Nine of the 15 studies in this worldwide synthesis explored gender differences in vocational education effects, and each found larger effects for females in the form of higher wages (Delajar, 2006; Chong \& Galdo, 2006; Attanasio et al., 2011; Alzuá \& Brassiolo, 2006; Díaz \& Jaramillo, 2006), employment (Ibarraran \& Rosas-Shady, 2006; Attanasio et al., 2011; Aedo \& Nunez, 2003; Alzuá \& Brassiolo, 2006; Delajara, 2006; Díaz \& Jaramillo, 2006), formality of employment (Attanasio et al., 2011 ; Alzuá, \& Brassiolo, 2006), and income diversification (Chun \& Watanabe 2011).

Further, while women may have received larger returns from vocational education programs, they were less likely to sign up for a vocational education program, were more likely to sign up for more "female-dominated" vocational fields, and might not have been aware of the relative returns to various vocational sectors (Hicks et al., 2011). Examining their baseline data, Hicks et al. (2011) found that males have a strong preference for traditionally maledominated fields (e.g., moter vehicle mechanics), whereas females tend to choose more femaledominated fields (e.g., hairdressing). The authors stated that "given these apparent misperceptions about the returns to vocational training and the pervasive occupational segmentation by gender, the provision of additional information and encouragement could have meaningful consequences for individual educational investment choices" (p. 4).

Thus the authors included in their vocational education information session a portion devoted to highlighting the disparity between the average earning of graduates in male-dominated versus femaledominated trades. They also used a video featuring a successful female car mechanic in order to encourage women to choose these more highly-rewarded trades. The authors found that females exposed to the information intervention were almost nine percentage points more likely to express a preference for a maledominated course, and five percentage points more likely to actually enroll in one; younger and more educated females were especially likely to prefer male-dominated fields. Thus to the extent that women are better informed about the relative returns to various types of vocational programs and are strongly encouraged to participate, there is the potential for strong growth in these vocational fields. 
Public versus private vocational programs. There is limited and only suggestive evidence that private vocational programs may yield better results than public programs. As described above, Bettinger et al. (2010) found that 5th grade voucher winners had higher completion rates, higher retention rates, a higher probability of taking the university entrance examination, and higher reading achievement than students that lost the vocational education voucher lottery. Again, the authors hypothesized that this is due to the fact that voucher winners were more likely to find a better match to their interest area given that they had their pick of all private sector vocational opportunities and that these private organizations may be better able to adapt their offerings to the demands of the labor market (in this case the growing service sector). Also in Colombia, Medina and Núñez (2005), using a propensity score matching methodology, evaluated the impact of public versus private vocational programs on student outcomes and found that private institutions offer a larger wage advantage to adults (both genders), as well as to male youth. In addition, Hirshliefer, McKenzie, Almeida, \& Ridao-Cano (2014), in a randomized trial of vocational programs for unemployed youth in Turkey, found that the short-term impact of the training on the quality of employment was positive and statistically significant, and that this impact was even stronger when the training was offered through private providers. However, of note are that these gains were not sustained past three years, and that the program had only a slightly positive and statistically insignificant impact on employment itself.

Hicks et al. (2011) conducted a similarly designed experiment in Kenya, but only their preliminary results are available. Thus far, they found that individuals who were awarded restricted vouchers (these could be used for public institutions only) were approximately 16 percentage points more likely to drop out, compared to those who were awarded unrestricted vouchers (these could be used for either public or private institutions). The authors argued that this made sense, given that restricted vouchers are less flexible to individual choice but that it is too early to make conclusions about differential employment across treatment groups (the program is still in the implementation phase).

\section{Limitations and Implications}

Drawing from the above sample of impact evaluations, it seems clear that vocational education programs benefit from tight linkages to targeted industries or firms-either through an internship or on-the-job portion of a training program (preferably paid so that the industry has an incentive to hire the student in which they have already invested); the tighter this link, the more successful the intervention from the standpoint of the student (Card et al., 2011; Chun \& Watanabe, $2011)$. Ideally, industries would use this portion of a vocational training program to screen for future employees, or vocational education programs could work as a "feeder" program into firms.

Because high quality training institutions have been shown to have a much higher impact on students, it is recommended that vocational programs included in any large-scale intervention be chosen through a competitive bidding process in which the following factors may jointly determine program quality: legal status (formality), the level of human resources and infrastructure, physical equipment, appropriate coursework or curricular structure, class size, expenditures per trainee, teacher quality variables (experience, education, etc.), and variables characterizing the link between the content of the training courses and the institution's knowledge about workers and occupational analysis of labor demand (Attanasio et al., 2011; Chong \& Galdo, 2006; Díaz \& Jaramillo, 2006). In addition, if the organization in charge of implementing the vocational education program can also function as a job placement and counseling organization, this can be an efficient way in which to track students and ensure their success. Furthermore, policymakers should not rule out the possibility of working in some capacity with the private vocational sector as there is preliminary or limited evidence that private vocational schools may be more able to adjust to changing market demands. That said, in the case of an economic stagnation, it is possible that individuals that trained in private vocational schools may face structural unemployment due to the more targeted (and thus narrower) skill set offered by these demand-driven institutions.

Overall, it seems that a country's economic context (for example, level of unemployment, market structure, or level of informality or formality) may determine the level of success of various vocational programs, possibly more so that then characteristics of these interventions themselves (this may explain the very mixed results from the 35 different vocational education evaluations). However, regarding gender, 
certain patterns do emerge: women's presence in the vocational education field seems to be an untapped resource as women consistently seem to benefit more from vocational training than their male counterparts (Aedo \& Nunez, 2003; Alzuá \& Brassiolo, 2006; Attanasio et al., 2011; Chong \& Galdo, 2006; Chun \& Watanabe 2011 ; Delajar, 2006; Díaz \& Jaramillo, 2006; Ibarraran \& Rosas-Shady, 2006) but are also less likely to sign up for vocational training or, if they do sign up, are less likely to choose the vocations with higher returns (currently these are male-dominated fields) (Hicks et al., 2011). Recommendations thus include heavy marketing to women to increase their participation in the vocational sector and the need to encourage women to take up vocations with higher rates of return.

\section{Apprenticeships}

\section{Katharine Conn}

An apprenticeship is a form of on-the-job training that is characterized by training under an employer or master craftsperson in exchange for a period of continuous labor. Apprentices often gain their license or accreditation to practice their trade or profession upon completion of their training. In some cases, on-the-job labor is accompanied by more formalized coursework or study. Formalized apprenticeship programs are very common outside of the Unites States where vocational education is the more dominant form of industry-specific training. Consequently, the majority of the rigorous literature in this area comes from Europe in particular. This section explores the efficacy of apprenticeship training programs. It includes a description of the literature as a whole (program targets, publication types, outcomes, methodologies, regions covered, etc.), the relevant findings associated with this body of work, and any limitations or implications of these studies. Note that while informal apprenticeship programs are common in developing countries (particularly Africa) ${ }^{6}$, there is limited experimental or quasi-experimental literature on the success of this type of informal training.

\section{Literature Description}

Twenty-seven efficacy studies regarding the impact of apprenticeships on youth outcomes were identified for inclusion in this synthesis. ${ }^{7}$ In addition, one systematic review examining the impact of apprenticeships on life outcomes in Europe was also included in this review. The following section provides an overview of the characteristics of the studies found through the systematic review process.

Study Population. Of the 27 high-quality apprenticeship studies identified for this synthesis, all 27 targeted apprentices or trainees in the workforce.

Publication Type. Of the 27 high-quality studies identified under the apprenticeship approach, 18 are journal articles, while the remaining 9 are working papers.

6 For a discussion of these informal apprenticeships see Filmer, D., \& Fox, L. (2014). Youth Employment in Sub-Saharan Africa The World Bank: Washington D.C.

7 See Appendix $C$ for a description of the search strategy and search terms. 
Outcomes. Most of the outcomes examined in the apprenticeship literature focus upon individuallevel wages, wage profiles, length of time at a job, successful transition to work/ employment status, unemployment spells, participation in further education, responsiveness to firm closure, and promotion to management. Macroeconomic outcomes explored in these studies include countrylevel job turnover, employment growth, employment level, effects on capital, investment and skill ratio, and productivity (value added per worker and sales per worker).

Methodology. Of these studies, 8 used causal quasiexperimental methods such as matching, regression discontinuity, or instrumental variables, while the others employed a large range of rigorous non-experimental methods such as dynamic discrete choice models, survival analysis, multivariate probit models controlling for endogeneity and self-selection, or proportional hazard models.

Region. Of these 27 apprenticeship studies, 14 take place in Germany, 3 in Switzerland, 2 in Austria, 1 joint study in both Germany and Switzerland, and 1 study in each of the following countries: France, Denmark, the Netherlands, Italy, Romania, the United States, and the United Kingdom.

\section{Findings}

It is important to note that the efficacy literature on apprenticeship training come from the developed world, and with the exception of one study in the United States, this literature is from Europe (Germany in particular). This is due to the fact that formal apprenticeship programs are well established in this region of the world and supported by the European Centre for the Development of Vocational Training (Cedefop), and while they may be spreading to other regions (Singapore for example), rigorous evaluations of these programs are essentially limited to Europe.

The findings of these studies cover seven major themes: country-level factors influencing apprenticeship provision, the positive rates of return to apprenticeships, the impact of apprenticeships on transition to employment and length of employment, whether there is a real apprenticeship advantage, the long-term benefits of apprenticeships, the heterogeneous effects associated with apprenticeships, and the impact of apprenticeships on the macro economy.

\section{Country-level factors influencing apprenticeship} provision. As to why apprenticeship programs are so widespread in only certain countries, Acemoglu and Pischke (1998) argued that whether or not firms provide apprenticeship training is related to general equilibrium variables such as job turnover (as well as the cost of firing workers) within a county. For example, in the United States where job turnover is high, this may be a disincentive for a high training outcome, as firms will not be willing to invest in workers that have a high probability of leaving, whereas in Germany where workers do not quit as often, there is a higher incentive to offer apprenticeship programs. Interestingly, the authors noted that while the investment margin is less distorted in a high-training equilibrium, this scenario may still result in a worse allocation of worker-job matches because workers may not be free to pursue their interests and needs.

Other factors influencing the scope of apprenticeship offerings include economic downturns; Brunello (2009) found that countries/firms are less likely to increase their share of new apprentices during a recession; they instead shifted their focus to training incumbent staff. Further, the costs associated with apprenticeship programs also depend on country-level factors such as relative wages between types of workers and the share of productive tasks given to apprentices within firms; these main factors are said to account for the differential costs of German versus Swiss firms offering apprenticeship programs (Wolter, Mühlemann, \& Schweri, 2006; Dionisius et al., 2009).

Positive rates of return. Numerous studies reported the positive upfront effects of apprenticeships on wage returns. Three studies from West Germany and Germany, spanning three decades reported positive rates of return to apprenticeships: Adda, Dustmann, Meghir, and Robin (2010) for West Germany from 1975-1996; Clark and Fahr (2002) for Germany from 1984-1995; and Werwatz (2002) for Germany in 1996. In addition, Mclntosh (2007) measured positive rates of return to apprenticeships in the United Kingdom from 1975-1998; Rezin and McCaslin (2001) found positive wage returns to apprenticeship programs in the United States (Ohio) from 1993-1998; and Fersterer, Pischke, and Winter-Ebmer (2008) found significant earnings returns in Austria for the period 1975-1998.

\section{Impact on transition to employment and length of unemployment. Two studies cited the impact of} apprenticeships on finding immediate employment: Bonnal, Mendes, and Sofer (2002) in France and Rezin and McCaslin (2001) in the United States (Ohio), while Malamud and Pop-Eleches (2010) found that there is no advantage for apprenticeship programs (versus general education) in Romania from 1995-2000. Regarding the length of unemployment, Bonnal et al. (2002) (France), Hofer and Lietz (2004) (Austria), and Parey (2009) (Germany), found that apprenticeships 
tend to reduce the amount of time spent between employment spells.

Is there a real apprenticeship advantage? When the returns to apprenticeship programs are compared against the returns to a high school diploma or a more traditional vocational education program, it is unclear if there is an apprenticeship advantage, though there is only limited evidence in this area. Parey (2009) found that there is no significant difference in wage returns between vocational school graduates and apprentices in Germany between 1975-2001. And in Austria, Hofer and Lietz (2004) found an apprenticeship advantage over individuals who complete only compulsory education; however this advantage disappears (and becomes negative) when comparing apprenticeship returns to those of high school graduates (from 19931998). Finally, in Switzerland, Bertschy, Cattaneo, and Wolter, (2009) found that full-time trainees in vocational schools are in fact less likely to find an appropriate job match than those who completed apprenticeships.

Benefits of apprenticeships may diminish over time. The long-term benefits of apprenticeships programs are not as strong, on average, as the short-term benefits. Adda et al. (2010) found that apprenticeships in West Germany increase wages and alter wage profiles with more growth initially, while wages for non-apprentices grow at a lower rate but for longer. In France, Bonnal et al. (2002) also found that while apprenticeships have a positive impact on employment duration overall, for those individuals who do not find employment immediately, having completed an apprenticeship becomes a "penalty rather than an advantage" (though this applies to only a small subset of the apprenticed students) (p. 438). Further, in Germany, Caliendo, Künn, and Schmidl (2011) found that after 3060 months, apprenticeships have a negative effect on employment (though a positive impact on further education). Hofer and Lietz (2004) in Austria found that the differential between wage returns of high school graduates and former apprentices tends to widen over time (in favor of high school graduates). And finally, Groot and Plug (1998) examined the long-term impact of apprenticeships versus school based vocational education in the Netherlands, and found that there are no significant differences between these groups in terms of earnings, earnings growth, or employment for years 1985-1994.
Heterogeneous effects of apprenticeships. The impact of an apprenticeship program on wages or employment may also vary by factors such as previous educational performance, occupational choice, gender, or size of training firm. Regarding previous performance, Buchel (2002) found that students with a high-quality school-leaving certificate in West Germany were more likely to have access to a "good" apprenticeship and were also less likely to experience negative effects regarding the schoolto-work transition. Further, Goggel and Zwick (2012) found that within industrial occupations, individuals who change employer or occupation enjoy wage advantages, while within the fields of commerce, trade, construction, and crafts, individuals face large wage losses from an occupational change.

Regarding gender differences, Hofer and Lietz (2004) found that the wage returns to female apprentices are not significantly different from those of female unskilled workers in Austria; however, they did find that apprenticeship training does seem to assist women in finding more stable occupations. The authors argued that this finding stems from the fact that women who complete apprenticeships do so largely in more traditional low-return fields such as the service sector. Bonnal et al. (2002) found that the impact of apprenticeship trainings on employment probability is higher for men than for women. The authors were not able to account for this differential but do say that for women, having been trained in business or the hotel trade, facilitates employment; thus it is possible that women either do not pick apprenticeships in other fields, that women are more likely to search for parttime work at a lower pay, or that women have difficulty getting hired in non-traditional fields.

Finally, regarding heterogeneous effects on stayers (those who remain at their training firm postapprenticeship training) versus movers (those who leave), Acemoglu and Pischke (1998) in Germany (for years 1979-1985) found that stayers earned higher wages than those who leave their apprenticeship firm for other reasons (though not a statistically significant result at the $5 \%$ level). Conversely, Euwals and Winkelmann (2004) also in Germany, argued that while stayers have longer first job durations than movers, this advantage actually does not hold for wages during the years 1975-1995. The authors also found that the intensity of the apprenticeship (as proxied by wage rate and training length) was positively correlated with retention rates, first job durations, and post-apprenticeship wages. Finally, Bougheas and Georgellis (2004) in West Germany, found that among occupational movers alone, apprentices trained in 
large firms earned a higher wage than those in small firms.

Effects of apprenticeships on the macro economy. In addition to the effects of apprenticeship programs on individuals, these initiatives also have an impact on overall labor market statistics. Only one study was able to study such macro effects: In Italy, Cappellari, Dell'Aringa, and Leonardi (2012) studied the effects of the 2001 reform which liberalized apprenticeship contracts. This reform increased the turnover and the net employment of apprentice workers and reduced the cost of apprenticeship contracts so that firms were encouraged to substitute external temporary staff with apprentices. They found that this reform has had an overall positive effect on the economy with an increase in employment growth (+1.6\%), job turnover ( $+3 \%)$, employment level ( $+5 \%)$, value added per worker $(+1.5 \%)$, sales per worker $(+0.9 \%)$, and total factor productivity $(+1.6 \%)$. The effects on capital, investment, and skill ratio were not statistically significant however. In addition, Origo and Patrizio (2013) conducted a cross-country analysis using European panel data to explore the relationship between apprenticeship indicators and youth labor market outcomes and found that a higher frequency of apprenticeships was associated with higher youth (15-24) employment rates.

\section{Limitations and Implications}

As the rigorous efficacy literature on apprenticeship programs comes only from Europe, where these programs have a multi-decade history, drawing strong inferences from these programs to the rest of the world, including the developing world, is not recommended. However, within the European legal, political, and economic context, the following points synthesize the bulk of the literature addressed above:

- $\quad$ The decision to initiate national apprenticeship programs (and for firms to initiate apprenticeship programs) is based on numerous country-level factors such as job turnover rates (Acemoglu \& Pischke, 1998), trends in economic growth (Brunello, 2009), and relative wages (Wolter, Mühlemann, \& Schweri, 2006; Dionisius et al., 2009).

- Apprenticeships are linked to positive income returns, particularly in the short term (Adda et al., 2010; Clark \& Fahr, 2002; Fersterer et al., 2008; McIntosh, 2007; Rezin \& McCaslin, 2001; Werwatz, 2002), though in the long term these returns may decline (Adda et al., 2010; Groot \& Plug, 1998; Hofer \& Lietz, 2004).

- Having completed an apprenticeship is associated with shorter unemployment spells (compared to unskilled workers) (Bonnal et al., 2002; Hofer \& Lietz, 2004; Parey, 2009) and an increased probability of finding immediate employment (post-apprenticeship) (Bonnal et al., 2002; Rezin \& McCaslin, 2001).

- When compared to individuals who have completed secondary education or vocational education training (VET), the results for apprenticeship training are more mixed (Parey, 2009; Hofer \& Lietz, 2004; Bertschy et al., 2009).

- $\quad$ Returns to apprenticeship training are higher for men (partly due to the fact that women are more likely to complete apprenticeships in more traditional and lower-wage sectors) (Bonnal et al., 2002; Hofer \& Lietz, 2004), and there is limited evidence that apprenticeship returns are higher for students with initially high quality education credentials and for those that complete more "intense" or prestigious apprenticeships.

- There are very limited findings regarding the macroeconomic impact of apprenticeship reforms, but evidence from Italy suggests that liberalizing the apprenticeship system may generate productivity returns (Cappellari et al., 2012).

Finally, a new randomized study, whose implementation is currently underway, attempts to measure the impact of a newly established national apprenticeship program in Ghana (Lehrer, Mbiti, \& McCasland, 2014). This will be the first national apprenticeship program with a rigorous evaluation outside of Europe. An innovative payment scheme accompanies this nation-wide program in which providers (firms) are paid based on their performance (based on the skill level and employment outcomes of their apprentices). The cost-effectiveness of this program will also be evaluated by the authors in order to inform other developing countries about the potential pay-offs associated with such an endeavor. 


\section{Cooperative Education}

\section{Elizabeth Park}

This section explores the efficacy of cooperative education, a form of work-based learning which integrates classroom instruction with alternating periods of paid discipline-related work experience. Cooperative education programs are normally offered at the post-secondary level. In 1906, during his tenure as Dean of the University of Cincinnati, Herman Schneider first developed the concept of cooperative ("coop") education with the first coop class of 27 engineering students and 13 companies (Cooperative Education \& Internship Association, n.d.). Coop education has since grown to be widely accepted in the United States and beyond in fields other than engineering (e.g., business, health, liberal arts). Coop education structures academic education with practical work experience by providing academic credit for work experience. Coop students typically participate in school-work rotations that may span as many as three academic years in four-year colleges (shorter periods in community colleges and high schools). The coop experiences are either full-time (40 hours of work per week) with alternating periods (semester, quarter) of work and school, or part-time (20 hours per week) combining work and school during the same time period. The underlying idea is that by working in professional environments during their student years, students will be more committed to their career choice, be more motivated to study, and acquire strong work transition skills.

\section{Literature Description}

Seventeen studies on the impact of coop education were identified for inclusion in this review. The following section provides an overview of the characteristics of these studies.

Study population. Three of the 17 studies looked at high school students or high school graduates. The majority of the remaining studies looked at students at the post-secondary level including university, college, and community college students.

Publication Type. Of the 17 coop education studies identified for this synthesis, 16 are journal articles. One is a synthesis and advocacy report.

Outcomes. Most of the studies focused on the students' performance during schooling (GPA, duration of completing education, retention), returns to cooperative education (wages, condition of employment status), and on students' psychological conditions, including perception of the program and feelings of self-efficacy.

Methodology. None of these studies employed randomized controlled trials, and only one employed some form of matching (propensity score matching). The remaining studies employed a mixture of methods including comparisons of non-equivalent groups and regression analysis with controls. Data were collected through school records and/or student surveys. Region. The studies in this sample are mainly from the United States, with the exception of 3 studies from Canada.

\section{Findings}

This section synthesizes the findings of these coop education studies into the following major themes: coop education at the secondary school level, coop education at the post-secondary level, completion of the program and retention at school, work-related outcomes, impact on job placement and persistence, and impact on self-efficacy.

Cooperative education at the secondary school level. Coop education programs at the secondary school level in the United States expanded when the federal Government passed the School-to-Work Opportunities Act (STWOA) in 1994. This act provides initiatives for work-based learning activities and opportunities that bridge the gap between school and work. This act also provides funds to states to establish coop education programs and provides financial incentives to employers to hire coop education students (Richard, Walter, \& Yonder, 2013).

Several studies have explored the impact of cooperative education on a variety of outcomes. One research synthesis of studies completed after 1994, focused on research reporting on the impact of the school-to-work initiative on students, teachers, and employers. The synthesis suggested that, overall, students who participated in work-based learning had greater attendance, were less likely to drop out of school, and were more likely to view work as a way to learn new things and prepare for the future (Hughes, Bailey, \& Mechur, 2001). Further, an analysis of the impact of a sixty-hour work-based internship program at a large Midwest urban school district in the United States found that social support from adult supervisors, and in particular student mentors, positively influenced students' occupational engagement (Bennet, 2007) 
(Note that this analysis was based on self-reported student survey data alone).

Another study using propensity score matching (between coop education participants and non-coop education participants) and data from the Educational Longitudinal Study of 2002 found that participating in cooperative education in high school had a significant positive effect on at-risk students' post-secondary education plans including students' plans to go to school right after high school, plans to continue education at some point in the future, and the type of school they planned to attend (Gemici \& Rojewski, 2010). However, they found no difference in students' thoughts regarding the importance of work, including the importance of gaining steady employment, obtaining a good job, being successful in one's chosen line of work, and being an expert in one's field by participation in a cooperative education program.

Findings regarding the impact of coop education on high school students' academic performance have been mixed. Exploring whether coop and non-coop students' GPA varied based on the number of hours worked per week, Stern, Finkelstein, Urquiola, and Cagampang (1997) found that among high school students, working longer hours was associated with lower academic performance, but the negative effect was much less pronounced among coop students. A study of career and technical education examined the extent to which high school students' participation in cooperative education is correlated with their scores on National Occupational Competency Testing Institute (NOCTI) exams-a measure of the effectiveness of career and technical schools (Richard et al., 2013). Students who participated in a coop program scored significantly higher on both written and practical portions of the NOCTI overall, as well as within individual program types with the exception of the carpentry and the childcare programs.

\section{Cooperative education at post-secondary level.}

Several studies investigated the association between participating in a cooperative education program at the post-secondary level and school outcomes, including GPA and duration in school. Blair and Millea (2004a) found that among engineering and business students at Mississippi State University (MSU), coop students had higher average GPAs than non-coop students, though this finding did not hold true for other majors. However, note that this study did not compare student populations that were equivalent; coop students were compared to students who may or may not have been eligible for the coop program. Blair and Millea (2004b) also reported that students who successfully completed the cooperative education program (defined as completing all three semesters) demonstrated higher academic performance as measured by their GPAs than students who were not enrolled in cooperative education. However, they found no difference between the GPAs of students who did not complete the coop program and those who did not enroll in the program at all (again this study also did not compare equivalent student populations). Looking specifically at MSU engineering majors, Blair, Millea, and Hammer (2004) found that coop engineers earned higher average GPAs than their non-coop engineering peers. However, to account for the potential bias of academic performance requirements for cooperative education programs, they compared coop eligible students with coop enrolled students, and found that students who successfully complete the cooperative education program graduate with higher GPAs than their non-coop peers who were eligible to enroll in the program. Although the results of these studies are somewhat mixed, overall they find that completion of a coop program at the post-secondary level has a positive impact on academic performance.

\section{Completion of the program and retention at}

school. Studies examining the relationship between cooperative education and duration in school found that participation in coop programs extended the time needed to graduate by about two to three semesters (Blair \& Millea, 2004b; Blair et al., 2004). However, over half of that time was spent gaining work experience through the program. It was hypothesized that compensation from the work periods in coop education programs could help pay for some part of students' educational expenses. Thus, it could be speculated that students might need to stay longer to complete the degree. This topic of inquiry, however, was not identified through the systematic literature search.

Avenoso and Totoro (1994) looked at the impact of coop education on students' retention in school by examining data from four entering classes from 1989-1992 at Long Island University's Southampton Campus. They compared two groups-students who were placed in cooperative education programs as freshmen and sophomores versus their non-coop peers. Based on the official college records, the authors found that the retention rate of the cooperative education students was significantly higher than that of the non-coop students. Although the authors checked the equivalency of the two comparison groups at baseline by comparing their SAT verbal scores, this is not enough to establish that the two groups were comparable across all observable characteristics. Thus, the issue of selection bias, coupled with the study's small sample size warrants caution in assuming a causal 
relationship between retention and the cooperative education program. Finally, Jaeger, Eagan, and Wirt (2008) examined the influence of coop education on the persistence of science, math, and engineering students entering in 1997 and 1998 at a large public university. The study found that $27 \%$ of all students dropped out before completing the degree. Students who participated in a coop education program were more than five times as likely to be retained compared to their peers who did not have coop education experience.

Work-related outcomes. Earlier non-experimental studies on the impact of cooperative education on starting salaries reported mixed results. Dubick, McNerney, and Potts' (1996) analysis of computer science majors from a Midwest university found that graduates with cooperative education experience had higher starting and current salaries than their peers without coop experience. In contrast, accounting for pre-existing differences between coop and noncoop students among both high school and two-year college students, Stern et al. (1997) found no difference in earnings. Using data form North Carolina community colleges, Wessels and Pumphrey (1996) examined the impact of the cooperative education experience, as well as the institutional effect of attending a school that offers cooperative education, on starting salaries; the institutional effect of coop programs increased wages by $7 \%$ for females $(p<.05)$, while there was no direct effect from participating in cooperative education itself. For males there was no difference in the starting salaries between coop and non-coop students, or between students attending a school offering coop programs and those attending a school that did not offer coop programs. Further, Blair and Millea (2004a) compared 5,506 coop and non-coop engineering, business, and other program graduates at the Mississippi State University and found that on average, coop students earned significantly more (over $\$ 6,000$ ) than non-coop students. However, the salary benefits associated with cooperative education varied across majors. In engineering for example, coop graduates on average earned more than their non-coop peers, but business majors in cooperative education programs earned less than their non-coop peers.

Three non-experimental studies explored earnings among Canadian college and community college students. An earlier study by Darch (1995) analyzed data from a survey of 1990 graduates and found that among those who were employed at the time of the survey, math and physical science graduates earned $\$ 5,490$ CDN more than non-coop grads in the same field. For commerce and economics, there was a
$\$ 3,700$ CDN premium for attending a coop program. Studies drawing on more recent data also found graduates of coop programs earned significantly more than their counterparts in traditional non-coop programs (Goho \& Rew, 2009; Walters \& Zarifa, 2008). Drawing on the National Graduate Survey from Statistics Canada in 2000, Walters and Zaria (2008) found that the earnings advantage for graduates with cooperative credentials was particularly strong among university graduates; they earned approximately $\$ 8,000$ CDN more per year than their counterparts with traditional (non-coop) undergraduate credentials. Similarly, Goho and Rew (2009) examined data from Canadian community college students and their analysis indicated that recent cooperative program graduates were more likely to be employed, to be employed in positions related to their education, and to have somewhat higher earnings than non-coop program graduates. Graduating from a cooperative education program resulted in an increase in monthly wages of about $4.8 \%$.

Impact on job placement and employment retention. Studies find that coop programs have a positive association with job placement and employment retention (Dubick et al., 1996; Wessels \& Pumphrey, 1995). Dubick et al. (1996) found that computer science graduates who participated in a coop program found employment more quickly than their non-coop peers; coop graduates were able to find employment in nearly two months less. While it took four months for coop graduates to reach $90 \%$ employment, it took non-coop graduates an average of nine months. Interestingly, Wessels and Pumphrey (1995) found that for North Carolina community college students, graduating from a college that offered coop programs was more of a factor in decreasing job search time than actually participating in a coop program. Furthermore, they also found that approximately $40 \%$ of coop students found their first job with their coop employer.

While the speed of job placement is important, job retention is equally important. Dubick et al. (1996) examined the relationship between participation in cooperative education and job turnover. Their results suggest that non-coop graduates changed employers significantly more often than cooperative education graduates. They also report that the combined effect of attending a college with a coop program and enrolling in a coop program was significant and positive for job advancement. However, according to Wessels and Pumphrey (1995), cooperative education has little impact on turnover. 
Impact on self-efficacy. Raelin et al. (2011) collected survey data on self-efficacy, which is defined as an individual's perceived level of competence to complete a task. In particular, this study formulated self-efficacy as a composite of work self-efficacy (confidence within the workplace), career selfefficacy (confidence within their chosen engineering career), and academic self-efficacy. Data were drawn from sophomore engineering students in four universities: Northeastern University, Rochester Institute of Technology, Virginia Polytechnic Institute, and the University of Wyoming. The authors found that overall self-reported ratings of work self-efficacy and career self-efficacy (though not academic self-efficacy) increased during students' sophomore years, regardless of whether they participated in a coop program or not $(p<.01)$. However, they also found that completing a cooperative education program had a positive impact on the work self-efficacy of students $(p<.01)$, whereas work self-efficacy decreased somewhat for those who did not participate in a coop program. They found no relationship between participation/completion in cooperative education and career or academic selfefficacy $(p>.05)$.

\section{Limitations and Implications}

As our systematic search yielded few studies using rigorous methods, it is difficult to reach a research consensus regarding the effectiveness of such programs. With such a small number of experimental or quasi-experimental studies, the results reported here may not be purely causal due to selection bias; that is, the individuals who choose to attend a cooperative education program may not be comparable to those that don't, thus any differences between these groups may not be differences fully attributable to the coop program alone. Further, the data used in a number of these studies was self-reported, which is potentially less reliable.

From the limited evidence available, however, it seems that cooperative education is a model that deserves consideration, as it appears to have high potential for connecting school experience with the workplace and for keeping students in schools. A number of the studies examined here indicated that students who completed cooperative education received higher starting salaries compared to non-cooperative education students (Blair \& Millea, 2004a, 2004b; Blair et al., 2004; Darch, 1995; Goho \& Rew, 2009; Walters \& Zarifa, 2008) and that coop education graduates spent less time finding a first job placement due to their prior exposure to the industry (Dubick et al., 1996; Wessels \& Pumphrey,
1995). Many cooperative education graduates found that the program raised their confidence level at work and helped them stay in school (Raelin et al., 2011 ). Additionally, cooperative education students' responses to program surveys indicated several factors that might make cooperative education programs stronger, including the importance of offering detailed guidance about industries in which students could be placed for work, providing continuous mentoring by adults while working, and implementing high-quality transition programs (Garavan \& Murphy, 2001; Nasr, Pennington, \& Andres, 2004).

\section{Career Academies}

\section{Wakasa Nagakura}

This section explores the efficacy of career academies, which are popular in the United States and have spread to several other countries. Career academies offer a form of work-based learning within an academic secondary school. Typically, these programs have career themes, show students the links between their academic subjects and a potential career, and involve employers and higher education institutions in preparing students for college and a career. A career academy usually operates in grades 9-12 or 10-12, and includes required academic subjects as well as career related classes, in order to ensure that students are eligible to enter university. Career academies encourage students to go to both 2- and 4-year colleges. In short, the three fundamental features of career academies are small learning communities, a college-preparatory curriculum with a career theme, and partnerships with employers and postsecondary educational institutions (Stern, Dayton, \& Raby, 2010). Their main objectives are to prevent students from dropping out and to encourage students to advance to post-secondary education or the workplace. This section includes a description of the career academy evaluation literature as a whole, the relevant findings associated with this body of work, and any limitations or implications of these studies. 


\section{Table 1: MDRC Studies/Reports on Career Academies}

\begin{tabular}{l|l} 
Year & Study title/Author
\end{tabular}

1997

Career Academies: Communities of support for students and teachersEmerging findings from a 10-site evaluation (Kemple)
Summary of findings

1. The Career Academies (CA) provided their students and teachers with a greater degree of interpersonal support and a strong professional community.

2. CA students were more likely to combine academic and career goals by participating in career awareness and work-based learning activities.
$2000 \quad$ Career Academies: Impacts on Students' Engagement and Performance in High School (Kemple \& Snipes)
1. CAs enhanced the degree of interpersonal support for students from teachers and peers.

2. Overall, more than a third of the CA students left the program before the end of their 12 th grade year.

3. Effectiveness varied among different risk level groups: the CA group had a lower dropout rate $(21 \%)$ than the non-CA group (32\%) and a higher average attendance rate (82\%) than the non-CA group (76\%).

4. CAs did not improve students' standardized test scores (reading/math).
$2001 \quad$ Career Academies: Impacts on Students' Initial Transitions to Post-secondary Education and Employment (Kemple)
1. Relative to similar students nationally, both CA and non-CA groups achieved higher rates of high school graduation, college enrollment and employment.

2. The two groups were comparable with respect to dropout rates from post-secondary education.
$2004 \quad$ Career Academies: Impacts on Labo Market Outcomes and Educational Attainment (Kemple)
1. The CAs substantially improved the labor market prospects of young men. The young men in the CA group earned over $\$ 10,000(18 \%)$ more than those in the control group over the four-year follow-up period.

2. The CAs had no significant impact (positive or negative) on the labor market outcomes for young women.
2008 Career Academies: Long Term Impacts on Labor Market Outcomes, Educational Attainment \& Transitions to Adulthood (Kemple)
1. CA graduates earned $11 \%$ more than non-CA members on average ( $\$ 2,088$ a year; $\$ 16,704$ over 8 years).

2. The impact was particularly strong for men, whose earnings increased by $\$ 3,371$ (17\%) per year or nearly $\$ 30,000$ over 8 years.

3. CA students demonstrated higher attendance, increased academic course taking and better on-time graduation rates.

\section{A. Literature}

Seventeen high-quality studies were included in this synthesis. ${ }^{8}$ The following section provides an overview of the characteristics of the studies found through the systematic review process.

Study Population. The study population for this set of studies consisted of high school students (9th-12th grade); multiple studies tracked these students through their post-secondary institutions and into the labor market as well.

Publication Type. Six of the studies in this section are journal articles; the remaining studies are working papers and evaluation reports.
Methodology. The methodologies ranged from Randomized Control Trials (RCTs) to matching group designs, and employed both quantitative (administrative student data), as well as qualitative data (interviews and classroom observations).

Outcomes. These studies assessed a wide variety of student outcomes; these include both academic outcomes (high school graduation rates, dropout rates, attendance, academic achievement, enrollment in post-secondary institutions, and increased-course taking) as well as labor market outcomes (employment status and earnings).

Region. Studies exploring the effects of career academies are limited to the United States. 


\section{Findings}

Since the mid-1980s, several studies have been conducted to evaluate the effectiveness of career academies; these have primarily used a matched comparison group design. In general, the researchers found that career academy students performed better than similar (individually matched) students in the same high schools, in terms of their academic performances and graduation rate (Reller, 1984, 1985, 1987; Stern, Dayton, Paik, \& Weisberg, 1989). Then, in 1993, the MDRC (Manpower Demonstration Research Corporation) launched a longitudinal evaluation study with a random assignment design. The MDRC study was conducted in ten different career academy sites focusing on preparation for various industries, including Business and Finance (Pennsylvania and Maryland), Public Service (Washington, DC), Aerospace Technology (Florida), Travel and Tourism (Florida), Health Professionals (Texas), Global Business (Califorina), Video (Califorina), and Electronics (Califorina). The initial sample size from the 10 sites was 1,952 students, but later the sample was reduced to 1,764 students at 9 schools: 959 students were randomly assigned to the program group and 805 students were randomly assigned to the control group at the end of 8th or 9th grade. The study collected data from school transcript records (students' daily attendance rates, credits earned toward graduation, and course-taking patterns); student surveys (school experiences, employment and work-related experiences, extracurricular activities, preparation for college and post-secondary jobs, and plans for the future); and standardized math, computation, and reading comprehension tests with a subsample of 490 students (from both groups). As the MDRC longitudinal randomized trial is the most rigorous and comprehensive study, its findings have been summarized in Table 1.

Overall findings from all 17 studies (both the earlier matching studies and the randomized MDRC studies) are discussed below and are grouped by outcome measures: academic achievement, post-secondary enrollment, and various workplace outcomes.

\section{Academic performance during high school and} high school completion. Several studies in the 1990s found that academy students performed better than similar students in the same high schools; students were matched on demographic variables and 9th grade records, including grades, high absenteeism, and disciplinary problems. Academy students on average showed significantly higher outcomes in school attendance, credits earned toward high school graduation, grade point average (GPA), and retention through high school (Stern et al., 1989). Within the 10 academies studied by MDRC, however, the impact on academic performances varied across sites. Although the MDRC sample demonstrated higher academic outcomes for career academy students in "completed credits to graduate," they did not show improvement on standardized measures of reading and math achievements or GPA (Kemple \& Snipes, 2000). Similarly, academy students at the National Academy Foundation (NAF) schools, who were interested in finance or the travel industry, did not have higher GPAs than their non-academy peers (Orr, Bailey, Hughes, Karp, \& Keinzl, 2004).

With respect to the issue of dropping out, the NAF report found that $92 \%$ of the career academy seniors "did not think about dropping out" while only $84 \%$ of non-academy students "did not think about dropping out," a statistically significant difference. The actual dropout rate of the students, however, was not reported. Kemple (2008) reported that approximately $75 \%$ of the academy students graduated from their high schools on time compared to $65 \%$ of similar non-academy students from similar school districts. Kemple and Snipes (2000) compared the dropout rates among academy and non-academy students, and there was no significant difference among all sampled students ( $10 \%$ for academy students versus $12 \%$ for nonacademy students).

However, when focusing only on high-risk students (based on selected background characteristics and prior school experiences), it was found that the program might have a larger impact on dropout rates (dropout rates were $32 \%$ for non-academy students versus $21 \%$ for academy students). Also, academy students showed a significantly higher average rate of attendance throughout high school when only the high-risk subgroup was considered (attendance rate of $76 \%$ among non-academy students versus $82 \%$ for academy students). It seems that participation in an academy made a significant impact; however, these results should be interpreted with caution, as around $30 \%$ of the students who enrolled in the academy programs studied by MDRC left the program before graduation, switching to other programs in the same high school or moving to different high schools. Kemple (2008) suggested, "Academies may be able to influence students' behavior and performance for only a year or two before students move on to other opportunities" (p. 11).

In one study, Stern et al. (1989) conducted a costbenefit analysis of the program. To do this, they estimated the number of dropouts saved in each 
academy by comparing the number of actual dropouts with the number that would have occurred if academy students had been included in the comparison (non-academy) group. In this sample $(n=327)$, it was estimated that 30 dropouts were saved, valuated at \$41,000 per dropout. With their cost-benefit calculation formula, the authors concluded that the dropout prevention program for this cohort saved between 11.3 million dollars. ${ }^{9}$

\section{Enrollment and academic outcomes in post-secondary}

schools. Career academies are expected to produce a positive impact on post-secondary school enrollment and academic outcomes within schools. Educational aspirations for advancement to post-secondary education is one of the outcomes investigated in this literature (Castellano, Stone, Stringfield, Farley-Ripple, \& Overman, 2007; Rojewski et al., 2010). Castellano et al. (2007) found that educational plans and aspirations were higher on average for career academy participants. In contrast, Rojewski et al. (2010) did not find any long-term differences. The difference may be explained by the length of exposure to the program or timing of data collection: Castellano et al. collected all data while the students were still in school, whereas Rojewski collected data both when students were in 12th grade and two years after their program involvement, suggesting that the effect of career academies on future education aspirations might be stronger in the early years of high school. A second outcome that is frequently examined is the proportion of students who enroll in post-secondary education. Within the MDRC sample however, no significant differences between academy and non-academy students were found: the post-secondary enrollment rate of academy students was $54.8 \%$ versus $54.6 \%$ for non-academy students (Kemple, 2001, 2008).

From the late 1990s onwards, Maxwell (2001) and Maxwell and Rubin (2002) collected data consisting of information on applicants to degree programs at a medium-sized state university in California who applied from a single high school district. More than $90 \%$ of the district students were ethnic minorities and nearly $40 \%$ were from poor families (defined as eligible for free lunch). Maxwell (2001) followed the graduates from this district to the state university, regardless of whether they had attended the academies. They found that academy participation in fact negatively influenced admittance rates to a 4-year college by 22 percentage points. The authors were not able to explain the results, but speculated that high school administrators may have steered lower-performing students into the academies. The authors found some positive impacts: academy students were less likely to need remedial course work in English at university and more likely to receive a bachelor's degree by 4.3 percentage points.

Maxwell and Rubin (2002) extended their analysis to a comparison between single district data and national data drawn from the National Education Longitudinal Study (NELS), to examine if academy participation influenced the possibility of attending post-secondary schools. The authors found that students in academies experienced an 11.6 percentage point increase in their probability of attending a 2- or 4-year college compared to general track students. Also, participating in career academies increased the likelihood that students would attend a 4-year college by 17.9 percentage points.

Labor market outcomes. A career academy is supposed to provide its students with greater career awareness through work related courses and worklearning internship opportunities. Kemple (2008) found that "Academy students were much more likely than their non-academy counterparts to be exposed to such experiences as job-shadowing, career fairs, guest speakers from local businesses, and instruction in how to look for and apply for a job, prepare a résumé, and interview" (p. 9). One indicator used to measure the impact of career academies on labor market outcomes is monthly earnings. Kemple (2004, 2008 ) surveyed a sample of students approximately 96 months after their graduation from high school and found that on average, career academy graduates earned $11 \%$ more than non-career academy members $(\$ 2,088$ a year, or $\$ 16,704$ over eight years in total earnings). The increase in earnings for the academy students was more apparent among young men, while the impact was smaller among young women.

Page (2012) analyzed the MDRC's data to examine the impact of duration of actual academy enrollment on student outcomes, as the actual enrollment length varied among program participants. She measured the students' enrollment in the program by the number of years and tried to make a causal connection to monthly earnings: male students who remained enrolled in the academy throughout high school subsequently earned approximately $\$ 588$ more per month than non-academy students. More modest impacts were found among those who participated only partially in the program.

Castellano, Sundell, Overman, and Aliaga (2011) examined student surveys from two districts where the students were matched by a propensity score

9 For detailed calculation, see http://epa.sagepub.com/content/1 1/4/405.full.pdf 
matching method. The student surveys in one district showed that the academy students researched potential jobs and careers significantly more than the non-academy group $191.8 \%$ of academy students researched potential jobs versus $86.6 \%$ of nonacademy students); the data was not reported for the other district.

\section{Limitations and Implications}

Based on the findings of the above studies, the career academy model has high potential for encouraging students to stay in school and preparing them for college and the workplace. While a number of studies found that career academy students had more promising educational outcomes than their peers (in the same high schools) in terms of school attendance, credits earned toward high school graduation, GPA, and retention through high school, a more rigorous study (longitudinal RCT) conducted by MDRC found that the impact on academic performances varied across sites: Although studies in some sites revealed that career academy students have higher credit completion, students did not show improvement on standardized assessments or with GPAs. Additionally, though career academy enrollment was associated with higher graduation rates, the results on dropout rates were mixed. However, when focusing only on high-risk students, evidence suggests that the program had a positive impact on reducing dropout rates and increasing attendance rates.

Moreover, studies found mixed results of the impact of academies on educational aspirations for, admittance into, and enrollment in post-secondary education. With respect to labor market outcomes, academy students benefited from the work-related courses and worklearning internship opportunities and earned more than non-career academy students, but the increase in earnings varied by gender and the years of enrollment in a career academy program. However, the schools selected in these studies tended to be schools that implemented their career academy programs with high fidelity, thus these findings might not be representative of all career academies. For example, it was found that many academies diminished the provision of workrelated-learning over time, due to the parallel pressures to meet the high schools' academic standards (Visher, Altuna, \& Stefan, 2013). Thus, it is important to examine the context and environment of each individual career academy in order to assess its outcomes.

\section{Workforce Training through E-Learning}

\author{
Katharine Conn
}

E-learning programs, modules, and coursework offer alternatives to students in technical fields, as well as to those in the workforce seeking additional qualifications and skills. Such programs provide flexibility regarding both the timing and location of course content delivery, and can allow students to tailor their coursework to their skill set. This section explores the efficacy of e-learning programs for workforce preparation as well as workforce training. As in the previous sections, it includes a description of the literature as a whole (program targets, publication types, outcomes, methodologies, regions covered, etc.), the relevant findings associated with this body of work, and any limitations or implications of these studies.

\section{Literature Description}

Twenty efficacy studies in the field of e-learning for post-secondary young adults/adults were identified for inclusion in this synthesis. ${ }^{10}$ In addition, two metaanalyses and 30 high-quality non-experimental case studies, journal articles, and policy reports were included. The following section provides an overview of the characteristics of the studies found through the systematic review process.

Study Population. Of the 20 e-learning efficacy studies identified for this synthesis, 8 were targeted at medical students and health professionals, 3 were targeted at university science/ psychology students, 2 sampled graduate students in education or preservice teachers, 5 targeted vocational education students and industry technicians, 1 sampled business school students, and 1 employed a sample of community college students. While this sample of rigorous studies may seem unduly weighted to students in the medical field, this is partially reflective of the number of e-learning programs available in the field of medicine currently, as well as a tendency for the use of randomized trials for research within the medical sciences. 
Publication Type. Of the 20 efficacy trials identified for this synthesis, 18 are journal articles, 1 is a working paper, and 1 is a report.

Outcomes. The main outcome examined by this group of efficacy studies is student achievement or performance. The majority of studies provided an estimate of the average treatment effect, while a limited number assessed the impact on sample subgroups (low-income or low-performing students). Secondary outcomes include student satisfaction and attitude.

Methodology. Of the 20 e-learning-related efficacy studies, 18 employed the use of randomized controlled trials, 1 employed a matching strategy, and 1 employed an instrumental variables strategy.

Region. The majority of efficacy literature on e-learning is from the United States. Out of the 20 efficacy studies, 14 were conducted in the United States, 2 in Asia, 2 in Europe, one in the Middle East, and one in Latin America.

\section{Findings}

Based on the efficacy literature above, this section synthesizes the findings of these studies into two major themes: the lack of significant achievement differences between e-learning and traditional classroom teaching and the heterogeneity within these findings.

Lack of significant achievement differences. Of the 20 experimental and quasi-experimental efficacy studies included in this synthesis of e-learning in postsecondary education or the workforce, the majority (15) found that there was no statistically significant difference between in-class, traditional learning and online or computer-based learning in terms of student performance; in each case, the authors could not reject the null hypothesis that the means of each group (treatment and control), were the same. In addition, 4 studies found slightly positive and significant effects of online learning on achievement (versus a control group) (Schilling, Wiecha, Polineni, \& Khalil, 2006; Schoenfeld-Tacher, McConnell, \& Graham, 2001; El-Deghaidy \& Nouby, 2008), while one study found a negative and statistically significant impact of e-learning on achievement in a community college context (Jaggars \& Bailey, 2010).

The absence of a measurable difference in achievement between the two groups in the majority of studies (or even a slight advantage to the online group) held among a variety of young adult and adult learners: medical students and health professionals (Bello et al., 2005; Beyea, Wong, Bromwich, Weston, \& Fung, 2008; Benjamin et al., 2008; Harris et al., 2007; Hugenholtz, de Croon, Smits, van Dijk, \& Nieuwenhuijsen, 2008; Padalino \& Peres, 2007; Schilling et al., 2006; Schoenfeld-Tacher et al., 2001); business school students (Ocker \& Yaverbaum, 1999); university science and psychology students (Frederickson, Reed, \& Clifford, 2005; Sexton, Raven, \& Newman, 2002; Woottipong, 2013); graduate students in education and pre-service teachers (El-Deghaidy \& Nouby, 2008; Mentzer, Cryan, \& Teclehaimanot, 2007); and vocational education students and industry technicians (Benson et al., 2004; Day, Raven, \& Newman, 1998; Gilliver, Randall, \& Pok, 1998; Hairston \& Nafukho, 201 1; Inayat, ul Amin, Inayat, \& Salim, 2013 )." Further, this overall "no significant difference" trend seemed to hold, regardless of the length of the training sessions (as little as four weeks up to a full calendar year).

For example, Benson et al. (2004) used a quasiexperimental matching methodology (and sample population of 193 career and technical education students in three community colleges across three states in the United States) and found no significant difference in student achievement between online and campus-based delivery models. However, the authors provided limited evidence of balance among observable individual or course characteristics postmatching, casting doubt on the equality of these groups. Day et al. (1998) randomized 58 students in a technical writing course (in agri-communication) between three traditional lectures per week versus a blended learning course with two media-enhanced lectures plus a computer laboratory session. They found no significant differences between the achievement or attitudes of students in the web-dependent versus the classroom model. Inayat et al. (2013) used a pre-post achievement gains methodology in an evaluation of online and in-class programs in graphic/web-design at a vocational training institute in Pakistan; they found that for two courses, there was a statistically significant increase in performance but that in two other courses there was no such pre-post difference. One study evaluated the use of e-learning in the workplace itself; Hairston and Nafukho (2011) conducted a randomized controlled trail of 262 participants across six industries (retail, manufacturing, civil service, architectural, education, and trucking) and found that while the e-learning groups make larger performance gains, the difference was not statistically significant. Furthermore, Gilliver et al. (1998) evaluated an

11 This study employed a pre-post methodology, not an experimental or quasi-experimental methodology. 
e-learning course in financial accounting among 151 students at Singapore's Ngee Ann Polytechnic through a randomized-controlled trial and found that on average, there was no advantage to online learning; however, for students at either end of the ability distribution (low and high performers), there was a positive impact on learning, presumably due to the fact that the web-based learning platform allowed students to personalize their instruction by learning level and alter the pace of the work.

However, Xu and Jaggars (2013), in a quasiexperimental evaluation of online (versus face-to-face) programs across 34 community colleges nationwide, found robust negative estimates for online learning in terms of both course persistence and course grade. The authors' analyses further suggested that previous descriptive estimates of the impact of these e-learning programs may in fact underestimate the gap in performance of traditional versus online students, as online students in this study were arguably better prepared and more motivated than those that took traditional courses; thus the direction of the effect size bias may be in the opposite direction of what was previously thought.

Overall findings may mask heterogeneity. This "absence of a statistically significant difference" between online and face-to-face learning (in regards to achievement) was a conclusion also reached by a recent meta-analysis of e-learning studies with sample populations from kindergarten up to workforce training (United States Department of Education, Office of Planning, Evaluation, and Policy Development, 2010). However, Jaggars and Bailey (2010), in a response to the Department of Education, re-examined these studies and found that the primary driver of these results are studies that employ blended learning programs (and not fully online courses alone). Further, they found that among students who completed their online courses, achievement levels were comparable to students in face-to-face classrooms; however, online students were more likely to drop out of their courses. Further, Sitzmann, Kraiger, Stewart, and Wisher (2006), also used meta-analytic techniques to show that web-based training was more effective than classroom instruction only in web-based training where the trainees had control of the pacing, were able to practice, received feedback during training, and were in longer courses. Finally, the United States Department of Education (2010) found that online instruction that was collaborative or teacher-guided was more effective than independent online instruction; of these, they found that teacher-guided instruction had the highest pooled effect size (0.039 standard deviations).

\section{Limitations and Implications}

While the efficacy evidence of e-learning programs focuses largely on post-secondary populations in school or the workforce (and not unemployed workers), the evidence available suggests that on average, e-learning programs can be just as effective as faceto-face programs. However, the overall finding of "no significant differences between groups" may mask heterogeneous effects: there are poorer results and higher dropout rates for lower income online students (Jaggars \& Bailey, 2010) and potentially high impacts for students on either end of the ability distribution due to highly-personalized e-learning software (Gilliver et al., 1998). Further, meta-analytic evidence suggests that blended learning programs (and not fully online programs), as well as e-learning programs that involve extensive practice, feedback, and time commitments are key to any online learning advantage (Jaggars \& Bailey, 2010; Sitzmann et al., 2006); otherwise classroom instruction still prevails. Further, for courses that train students to interact with others (through teaching or business negotiations), student satisfaction was higher in face-to-face courses (Mentzer et al., 2007; Ocker \& Yaverbaum, 1999). Finally, online instruction that was collaborative or instructor-led was overall more effective than individualized learning (United States Department of Education, 2010).

These preliminary findings imply:

- $\quad$ Any e-learning training should pay careful attention not only to the average treatment effects but also to the progress made by multiple subgroups (by income-level, ability-level, etc.). In addition to learning, outcomes such as sample attrition in both groups should also be carefully monitored.

- E-learning programs should incorporate elements of instructor-led/blended learning (as opposed to fully online courses). Programs should also include a collaborative element.

Policy-relevant considerations. In addition to the efficacy literature (above), this review also includes a series of policy-relevant considerations for e-learning in Technical and Vocational Education and Training (TVET), based on academic descriptive or case study research and a series of UNESCO, the World Bank, and OECD reports. This set of considerations is not meant to be comprehensive, though they do encompass the major themes of recent policy-relevant research. The following paragraphs explore the need for ICT skill development, strategies for e-learning take-up, the quality of the pedagogical content, and the costs associated with implementing these e-learning training programs. 


\section{Need for Information and Communication Technology (ICT) skills development. Multiple studies raised} the issue of technical skills within both the student population and the teaching population that may need to be addressed before instituting any Information and Communication Technology (ICT) programs within vocational or workforce training. For example, Jinnah, Al-Mamum, Khan, and Hasan (2011) conducted a survey regarding the overall status of ICT in the Polytechnic Institutes of Bangladesh and found that both teachers and students lacked skills that would enable them to use ICT for their learning purposes due both to the poor quality of ICT infrastructure and to the poor ICT preparation of teachers. In addition, UNESCO (2013) found that a main concern in the implementation of ICT in TVET was that teachers were often not prepared to use ICTs in teaching and require additional training and targeted professional development in how to incorporate technology for improved educational outcomes. Further, Goertz and Johanning (2004), Bedwell and Salas (2010), and Dunn (2003) all emphasized the need for an initial needsassessment (for students, teachers, or employees) to better understand the individual computing levels, knowledge, and skills of all stakeholders before the implementation of any IT-based trainings.

Strategies for e-learning take-up. Various authors have offered suggestions regarding strategies to encourage the take-up of e-learning programs in the workforce. Among the challenges to the integration of IT into technical training in the South African manufacturing workforce was the need for employers to set aside adequate study hours for e-learning (Macdonald, Bullen, \& Kozak, 2010). This finding is echoed by Goertz and Johanning (2004) who also suggested that some degree of time-sharing (employers allot one hour per week of work time, while employees allot one hour per week of their leisure time) may be optimal. Goertz and Johanning (2004) also suggested that take-up could be increased though offering employees incentives, ensuring that the technical system is stable (to avoid frustration and drop-out), and through employing tutors and learning groups. Finally, Karaali, Gumussoy, and Calisir (2011) used structural equation modeling to determine factors that predict take-up of e-learning in the workplace, and they found that above all other variables, social influence has the highest predictive power, highlighting the importance of creating a workplace culture that is supportive of continuous professional development through web-based services.
Quality of pedagogical content. In the same way that an individual teacher can drastically influence the learning levels of students (in either direction), individual e-learning programs can also have such impacts. That is, e-learning programs are not effective in and of themselves, nor are they "ready-made," but instead they rely on specific pedagogical qualities and must be adapted to each context in order to be successful (Clark \& Mayer, 2013; Bedwell \& Salas, 2010; UNESCO, 2013). Curtain (2002), Dunn (2003), Bedwell and Salas (2010), and Clark and Mayer (2013) stressed the "importance of interactivity" for online learning and blended learning, in terms of both interactive and adaptive e-lessons as well as the interactivity of the students with other students and instructors. Mupinga and Busby (2011) highlighted a series of web-based, interactive simulation trainings used to improve students' technical skills. ${ }^{12}$ Regarding teacher-student interactivity, Clark and Mayer (2013) highlighted evidence that points to the importance of "guided discovery" as opposed to fully unguided discovery learning online. And UNESCO (2013) cited growing agreement among all stakeholders (vocational schools, government training programs, and industries) that "ICTs could and should be incorporated into TVET, although they are unlikely to replace in-class instruction" (p. 14). There is also a growing debate regarding the "degree of 'learner control'" (pace control, sequence control, content control, and advisory control) provided to the students, and may depend on the nature of the course; Granger and Levine (2010) found that increased "learner control" can be advantageous, but only within a certain realm of course complexity.

In addition, Bedwell and Salas (2010) argued that there are a series of "learning principles" that are critical for web-based training success (as well as face-toface learning). Among these are the importance of gaining the attention of the e-learning participant with an engaging introduction, delineating lesson objectives and activating motivation, initiating recall of prior learning, presenting stimulus material, providing learning guidance, eliciting performance, providing feedback, assessing performance, and enhancing retention and learning transfer. Clark and Mayer (2013) further argued that there needs to be a certain degree of learner scaffolding throughout any web-based lesson.

12 Examples of web-based simulation games aimed to teach technical skills include: Building Homes of Our Own; DimensionM Game Maker 8; Klik \& Play; MS Flight; Simulator; Ruler game; West Point Bridge Design. 
Costs associated with instituting ICT in TVET. Numerous authors cite the need for countries, schools, and industries to accurately assess the costs associated with any e-learning training platform. While there are certain economies of scale associated with large e-learning initiatives, the upfront costs associated with the creation of the programs can prove to be extremely high; costs to be considered include the software platform, up-front licensing fees, IT system administration and learning management system, pedagogical content (and support materials), information communications infrastructure, the initial training of teachers and students, and a supervisory organization and credentialing network (Paulsen, 2009; Bedwell \& Salas, 2010; Moran \& Rumble, 2004; Dunn, 2003). Large-scale ventures in ICT for TVET in the UK (Open Tech) and across Africa (African Virtual University) have proved difficult to sustain and grow due largely to these cost factors (Moran \& Rumble, 2004). This is particularly true for small and mediumsized enterprises (Paulsen, 2009). Further, Paulsen (2009), whose recommendations were derived from case studies of eighteen enterprises in eight European countries, suggested that small-sized enterprises with few employees may prefer to enroll in more generic e-learning courses, while medium-sized enterprises could benefit from more specialized courses (offered through branch associates or in partnership with suppliers or chains), whereas as large enterprises could afford to develop their own e-learning courses, tailored for internal use.

Benefits to ICT in TVET. While there are a number of important considerations which could affect the timing, scope, and success of an e-learning training, particularly in the developing world, the research and policy literature is still cautiously optimistic about the potential for ICT to transform vocational and technical training in the workforce. In particular, UNESCO (2013), found that:

1. "Good knowledge of ICTs combined with the resulting development of soft and transferable skills, in addition to the technical training provided, stands to benefit all students and teachers in the constantly changing jobs marketplace of today, forming a toolkit for long-term employability and success in the workforce" (pp. 14-15).

2. "The use of ICTs could improve both the quality and the perception and status of TVET, which is not currently held in high regard in many countries" (p. 15).
3. "There is great potential for job creation and economic growth to emerge from improved TVET and a knowledge-based economy if the benefits can be extended to wider parts of the population" (p. 15).

McKay and Vilela (2011) stressed the importance of continued evaluations of any e-learning program (they examined several training effectiveness models) in order to improve upon the content as well as the implementation. Finally, Weise and Christensen (2014), predicted that the future of higher education in the United States would be less focused on traditional academic routes, or even on the one- to two-year vocational or community college degrees, but would instead begin to prioritize "competency-based" e-learn modules (associated with particular technical skills). The authors argued that this type of "competencybased education" would allow students or employees to complete their training over their lifetime, continually forming a "stack of credentials," that can make them more marketable in the labor force. 
Chapter One || Skills Development 
Strategies for

Strengthening

the Technical

Workforce 


\section{Provision}

of Information

\& Incentives

A second solution domain offering strategies to strengthen the technical workforce is composed of two main strategies that seek to improve access to career and technical education: the provision of better information to students, their parents, and prospective employees; improvements in career counseling and employment services; and the provision of incentives to students in order to encourage participation or enrollment in a particular field.

This chapter first explores studies that examine the impact of providing information to students or parents regarding the returns to certain types of education, their eligibility for financial aid, or about the performance of schools in their choice set. In a knowledge-based economy, such information has the potential to greatly impact enrollment outcomes. Secondly, this chapter details the impact that information provision through career counseling and employment services can have on an individual's occupational choices; these studies examine the impact of career counseling and services on both subjective measures (career initiative, self-efficacy, and satisfaction) and objective measures (salary, career advancement/promotion, and employment). Lastly, this chapter examines the ways in which monetary incentive structures directed at students (scholarships, vouchers, etc.) can stimulate participation in education or skills training; the studies reviewed here explore the overall impact of monetary incentives on student outcomes, the impact when performance is incentivized, and the impact on specific groups including underprivileged subgroups and females. 


\section{Information Interventions}

\section{Katharine Conn}

While information interventions in this area are similar in that they focus on drivers of educational choice, the type of information provided in each case can be quite different. In this review, information provided to students and households includes: the rate of return to a particular educational investment, information on aid-eligibility, and information on relative school performance. Note that these information interventions were temporary in nature and not permanent features of an education system. This section explores the efficacy of these information interventions. It includes a description of the literature as a whole (study population, publication types, outcomes, methodologies, regions covered, etc.), the relevant findings associated with this body of work, and any limitations or implications of these studies.

\section{Literature Description}

Nine impact evaluations dealing with the effects of information provision on educational choices are synthesized here. The following section provides an overview of the characteristics of the studies found through the systematic review process and which are included in this synthesis.

Study Population. Of the nine studies that examined the impact of information on school choice, eight were targeted at students currently attending either primary or secondary school, and one sampled out-ofschool youth.

Publication Type. Of these nine studies identified for this synthesis, three are working papers and six are journal articles.

Outcomes. Studies that examined the impact of information provision on school choice examined outcomes such as school completion, dropout rates, attendance, academic performance, hours worked, submission of admissions and aid applications, and enrollment/attainment.

Methodology. Of these nine information studies, eight employed randomized controlled trials, and one employed a descriptive survey-based methodology.

Region. These information interventions took place in China (two), the Dominican Republic, the United States (three), Madagascar, India, and Canada.

\section{Findings}

Based on the studies above, this section synthesizes the results into two major themes: 1.) the impact of rate of return information on educational choice and 2.) the impact of aid eligibility and school performance information on educational choice.

Impact of rate of return information. Seven studies examined the following question(s): What happens when individuals are informed about the financial returns or the benefits of a certain type of education? Does this affect their school choice? Jensen (2010) conducted a randomized trial in which students (8th grade males) at randomly selected schools in the Dominican Republic were informed (by the survey enumerator) of the differential rates of return to primary, secondary, and tertiary education. He found that this information caused students in the treatment groups to complete on average 0.20-0.35 more years of school over the next four years than those who did not receive this information. Similarly, Nguyen (2008) in Madagascar, conducted a randomized trial in which teachers relay information to parents and 3rd/4th grade students about the true returns to schooling. Nguyen found that test scores improved by 0.37 standard deviations for those whose initial perceived returns were under the rate of return statistics, while student attendance in intervention schools also increased by 3.5 percentage points. Nguyen also experimented with the use of "role models" and sent a role model to share with students and families his/ her family background, educational experience, and current achievements. He found that this intervention was particularly impactful for poor students who were sent role models of initially poor backgrounds.

Adding more evidence to the theory that correcting an individual's perception of the returns to education can influence actions or beliefs, Oreopoulos and Dunn (2013) conducted a randomized experiment in Canada in which the authors presented students with an online survey and randomly sampled half of the students to receive a three-minute video within the survey about the benefits of post-secondary education (these students were also invited to try out a financialaid calculator). Students who were selected for the video reported higher expected economic returns, lower concerns about costs, and expressed a greater likelihood of continuing their education past the secondary level.

Finally, Mensch, Grant, Sebastian, Hewett, and Huntington (2004) examined the impact of an 
intervention in which reproductive health information, vocational counseling and training, and assistance with opening savings accounts were provided to adolescent girls in slum areas of Allahabad in Uttar Pradesh, India. The vocational counseling portion of this intervention put an emphasis on the importance of remuneration and savings, and consisted of the use of flip books that contained vocational flash cards with a description of courses available. The counselors (peer educators) also provided detailed information about short-term, non-formal training courses available in the vicinity, including courses offered by government institutes and NGOs, as well as those organized specifically by the project. While take-up of these vocational programs was very high, the authors reported that there were no statistically significant effects of the program on the number of hours women spent in the labor market or at training sessions. This lack of clear findings is likely due to the fact that the authors were only able to include a small subset of the treated participants in the analysis, as they were unable to clearly identify (and follow-up with) individuals that took part in the training.

Thus, while there is suggestive evidence that sharing information about the returns to a certain level of education may affect schooling decisions or beliefs, this is yet to be rigorously tested in the case of vocational education. A new study (Hicks et al., 2011) is examining this particular issue, but only preliminary results are available thus far. In this study, the authors paired a randomized evaluation of a vocational education voucher program with an information intervention in Kenya, in order to test whether the provision of information on the returns to vocational education (estimated in a Mincerian regression), would have an effect on voucher take-up (note information was presented verbally as well as through handouts and posters). At the outset, the authors found that the perceived rate of return to vocational education was quite high (61\%, compared to the actual value of $37 \%$ ). The authors found that this information intervention did not affect individual decisions to apply for a voucher or voucher take-up, though it did have an impact of the preference of females for more male-dominated courses (for more details on this gender component, see Chapter I of this paper, Vocational Education, Section B, "Differential Impact by Gender.").

Finally, in rural China, a randomized information intervention at the junior high school level was conducted in which students were provided with information regarding the income returns to high school education as well as counseling regarding the requirements for entering high school (Loyalka et al., 2013a). The authors found that information on income returns had no significant impact on student choice (this may be due to the fact that the rate of return to secondary education was no different from the rate already perceived by the students; the authors do not test this in their baseline survey). They did find, however, that counseling had a negative impact on student achievement and transition into high school; the authors surmised high school, in combination with the relatively high wages available in the unskilled sector.

\section{Impact of aid eligibility and school performance information. Three additional randomized trials examined the impact of providing information on post-secondary aid eligibility and on school performance in order to influence student educational choices. Hastings and Weinstein (2008) conducted a randomized experiment (and also used a natural experiment) that provided direct information about school performance (school test scores) to low-income parents under a public choice plan in the United States. They found that receiving such information did increase the probability that parents would choose a higher-performing school for their children, and that their children in turn would improve their academic achievement, which supports the hypothesis that the provision of performance information (which could be considered a form of "return on investment") can indeed have an impact on school choice.}

Secondly, in a randomized experiment in which H\&R Block tax professionals provide student aid eligibility information as well as assistance to low- to moderateincome families (in the United States) in the completion of the FAFSA, Bettinger et al. (2012) found that students who received this information and assistance were substantially more likely to submit the aid application, enroll in college the following fall, and receive more financial aid. Interestingly, these results did not hold for a secondary treatment group who received only aid eligibility information alone, highlighting the importance of in-person assistance. In addition, Kane and Avery (2004) gathered survey data on student perceptions of college opportunities, particularly among low-income students and found that the aspirations and expectations of these students are not overly pessimistic, thus interventions that don't go beyond providing information regarding aid eligibility (as well as information on other returns) may not prove to be sufficient to change the application behavior of low-income youth in the United States (study conducted in Boston public schools). These results support the findings of Bettinger et al. (2012) in that interventions that go beyond the simple provision of information may be the most compelling to youth, at least within the United States context. 
Finally, Loyalka, Song, Wie, Zhong, and Rozelle (2013b) conducted a randomized trial in rural China in which they provided high school students with information about college costs and financial aid opportunities. They found that this intervention raised the probability of students receiving some type of financial aid, particularly among females and low-income students. The intervention also increased the likelihood of college attendance, especially among females, raising the probability of female attendance by 10.7 percentage points, but with no significant effect on male students. However, the intervention did not seem to impact the type of college to which students applied (tier 1 and 2 versus others).

Online provision of occupational information. While there is no efficacy literature evaluating the impact of online employment websites or networks rigorously, there are organizational websites (publicly as well as privately run), which provide information across all categories of employment, including certain websites that specialize in employment positions with STEM fields, for example, the International Association for Educational and Vocational Guidance, Australian Apprenticeships, and Asia Pacific Career Development Association, among others. (see Appendix B for a complete list and accompanying websites).

\section{Limitations and Implications}

These recommendations are drawn only from the small sample of impact evaluations discussed above, but from this limited evidence across multiple countries, it seems that informing students of the returns associated with various levels of education can be effective in influencing school choice (Jensen, 2010; Oreopoulos; Nguyen, 2008; Mensch et al., 2004; Hastings \& Weinstein, 2008; Loyalka et al., 2013a; Loyalka et al., 2013b). Clearly, the nature of the information intervention may depend greatly on the country context and student population itself. Further, the extent to which these interventions may actually influence change partially depends on the degree of misperception in students' appraisal of income returns associated with a certain level of education. In Kenya, where individuals had overly optimistic perceptions of the rate of return to vocational education, it was not surprising that the provision of true returns information had no statistically significant impact on student demand for vocational education (Hicks et al., 2011). This is in contrast to the Dominican Republic where the rate of return to education was perceived as lower than its true value by the students in the intervention sample, and the impact of an informational intervention had a positive and statistically significant impact on schooling attainment (Jensen, 2010). In addition, the success of information interventions may also depend on the level of information technology and thus information dissemination mechanisms available locally. Finally, counseling and guidance regarding the options open to adults, the returns on those options, and assistance with filling out complicated forms, may generate an even larger impact on individual choices (Bettinger et al., 2012; Kane \& Avery, 2004). The next section provides a more in-depth review of such career counseling interventions.

\section{Career Counseling and Employment Services}

\section{Elizabeth Park}

The provision of information alone may not be sufficient to affect career choice or labor market outcomes such as salary, promotions, and employment. Career counseling, mentoring or formal employment services for both students and individuals already in the workforce can help to bridge this gap. This section explores the efficacy of career counseling and employment services. It includes a description of the literature as a whole (program targets, publication types, outcomes, methodologies, regions covered, etc.), the relevant findings associated with this body of work, and any limitations or implications of these studies.

\section{Literature Description}

Eighteen efficacy studies regarding the impact of career counseling on youth and current employees and professionals were identified for inclusion in this synthesis. ${ }^{13}$ The following section provides an overview of the characteristics of the studies found through the systematic review process and which are included in this synthesis.

Study Population. Of the 18 high-quality studies of career guidance identified for this synthesis, only 4 of them contained an intervention that was targeted at students currently in secondary school or in higher education: Fouad (1995) and Kerr and Robinson 
Kurpius (2004) focused on American secondary school students; Stoeger, Duan, Schirner, Greindl, and Ziegler (2013) focused on female German secondary school students; and Wu, Tsai, and Chen (2014) focused on students enrolled in 12 universities across Taiwan. The majority of the remaining interventions targeted currently employed and/or unemployed adults.

Publication Type. Of the 18 studies identified for this synthesis, 13 are journal articles, 3 are reports from international organizations, 1 is chapter from an edited book, and 1 study is a doctoral dissertation.

Outcomes. Many of the outcomes examined in the career counseling literature focused on subjective returns to counseling and mentoring (e.g., career initiative, self-efficacy, commitment, satisfaction). However, several studies addressed the impact of career counseling on objective success (e.g., salary, promotions, employment).

Methodology. Of the career guidance-related studies, 2 employed randomized controlled trials, 2 employed propensity score matching, 3 employed comparisons across nonequivalent groups, 9 employed correlations, and two synthesized findings from other evaluations.

Region. Of these 18 high-quality mentoring studies, 2 synthesized evaluations took place across the globe, 4 took place in Asia (in China and Taiwan), while the other 12 took place in America and Europe (including France, Germany, Romania, Switzerland, the United Kingdom, and the United States).

\section{Findings}

The career counseling and employee services-related studies identified for this synthesis generally reported that mentoring has a positive if not null impact on career initiative, self-efficacy, and satisfaction. With regard to the objective measures, most studies reported that mentoring increases earnings and promotes career advancement, but the results were mixed for employment.

Subjective Measures. A number of studies, explored in more detail below, examined the impact of career counseling and services on a series of subjective measures, which include: career initiative, self-efficacy, and career satisfaction.

Career Initiative: The career counseling-related studies identified for this synthesis tend to report that counseling has a positive if not null impact on career initiative. Stoeger et al. (2013) evaluated a one-year e-mentoring program focused on promoting girls' development in STEM and its effects on a number of outcomes relevant to potential future STEM careers: STEM activities, knowledge about university studies and jobs in STEM, and academic elective intentions. Although the results suggested that there was a positive relationship between career guidance and the outcomes described above, the short-term (6 months) initial increase in STEM activities was not maintained to the end of the program. One possible reason Stoeger et al. offered is that there is a typical decline in user activity after the initial phase of participation in online programs. During an initial phase in which subjects are getting to know their online community, participation rates are typically quite high. However, the rates normally fall precipitously thereafter.

Similarly, in a study on the self-efficacy of secondary school-aged students, Kerr and Robinson Kurpius (2004) conducted an analysis of an intervention called the Talented At-Risk Girls: Encouragement and Training for Sophomores, or TARGETS, project, which was created to enhance the career development of minority and low-income girls who had strong academic potential in math and science but who were at risk ${ }^{14}$ of not achieving their career goals. The results suggested that counseling interventions positively impacted career aspirations and increased career search behaviors that were likely to increase students' knowledge about careers in mathematics and science.

An earlier study by Fouad (1995) explored a one-year intervention that was designed to improve 8th grade minority students' awareness of and preparation for math and science careers. They found that the program was successful in increasing students' occupational knowledge and providing students with the knowledge to make deliberate decisions about high school. Although across all students there was a downward trend in academic achievement over the course of the year, in comparison to the control group, students who received counseling performed better in math and science courses than their counterparts.

Self-efficacy: While these studies offered very mixed definitions of self-efficacy and self-esteem, in general most studies reported that career guidance increased self-reported measures of ability and value. According to Fouad (1995), 8th graders who received counseling that infused math and science career awareness demonstrated greater self-efficacy after completing the treatment. Another study similarly found that for secondary school-aged girls, mentoring improved self-efficacy; the girls demonstrated higher scores on

14 Risk factors might include low self-esteem and self- efficacy, poverty, unsafe behaviors, or poor family support for goals. 
self-efficacy measures between the pre- and posttests (Kerr \& Robinson Kurpius, 2004). Similarly, Wu, Tsai, and Chen (2013) also found that career guidance had a positive impact on science education majors in Taiwan. The results suggested that the appropriate career guidance had a strong positive impact on the vocational self-concept $(b=0.58, p<.001)$ and selfperceived employability $(b=0.31, p<.001)$ among the science education undergraduates.

Although analyzing a different sample of professionals, Brennan (2009) also found that active-duty Coast Guards who received counseling have significantly higher levels of career decision-making self-efficacyincluding one's level of confidence of successfully engaging in tasks associated with making a career choice-as compared to the control group. In addition, Chang and Feng (2014) reported that career counseling strengthened the positive relationship between career competencies and subjective career success (defined as career growth and marketability) for employees of manufacturing companies in Taiwan. Similarly, Bernaud, Gaudron, and Lemoine's (2006) study of adults in the technical training, administration, trade, and communication industries suggested that the effects of career counseling appeared positive for self-efficacy. However, the correlation between counseling treatment intensity and the progress made in enriching self-concept by the participants were very slight and not significant. In contrast, Siebert (1999) found no association between mentorship and selfesteem among newly hired engineers overall. However, he did find that among individuals participating in the mentor program the intensity of the mentorship was positively related to self-esteem $(b=0.46 ; p<0.05)$.

Satisfaction: Overall, studies found a positive association between career counseling and career satisfaction. Despite variations in geographic location and industry, the studies included in this synthesis all reported that protégé and mentor experiences positively influence job satisfaction (Bernaud et al., 2006; Collins, 199415; Seibert, 1999; Pan, Sun, \& Chow, 2011 ; Gong, Chen, \& Yang, 2014). For example, based on the written responses from individuals in the technical training, administration, trade, and communication industries in France, Bernaud et al. (2006) found that for individuals who received career guidance, fulfillment at work seemed to be the most positive gain: $73 \%$ of the participants reported greater satisfaction at work since completing the career guidance process. Furthermore, according to Seibert's (1999) study of newly hired mechanical and electrical engineers at a Fortune 100 company, the intensity of the mentorship was associated with career satisfaction: higher levels of mentoring received by the protégé was associated with higher levels of job satisfaction $(b=0.34, p<0.05)$.

Addressing a different research question, Ragins, Cotton, and Miller (2000) explored whether satisfaction with mentoring is related to career attitudes. They were able to obtain a nationally representative random sample including social workers, engineers, and journalists. Among their findings were that protégés in highly satisfying mentoring relationships reported significantly greater job satisfaction than non-mentored individuals.

Objective Measures. The following section explores the impact of mentoring and career services on the following objective measures: salary, career advancement or promotion, and employment.

Salary: Although the majority of the studies included in this synthesis focused on subjective measures of career success, a few explored the relationship between mentorship and objective measures such as employment, career advancement, and salary increases. Although as reported earlier Chang and Feng (2014) found that career counseling strengthened the positive relationship between career competencies and subjective career success, counseling did not have a significant positive effect on the relationship between career competencies and objective career success, measured by salary in this study. Likewise, Collins (1994) found that involvement in mentormentee relationships did not have a significant impact on the income level of those who had been a protégé; however, it did in fact have a significant impact on the income level of mentors. ${ }^{16,17}$

Promotion: Career advancement is another objective measure of the effectiveness of career guidance programs. For instance, in their evaluation of marketing, administration, and finance employees of Taiwanese companies, Gong et al. (2014) found that

\footnotetext{
15 Professionals who had been both a protégé and a mentor had the highest level of career satisfaction, followed by those who had been a protégé but not a mentor, those who had not been a protégé but had been a mentor, and those who had been neither a protégé nor a mentor. 16 Professionals who had been both a mentor and protégé earned the highest incomes, followed by those who had been a mentor but not a protégé, those who had been neither a protégé nor a mentor, and those who had not been a mentor but had been a protégé.

17 Other studies that have explored the effect of being a mentor on career success found that becoming a mentor benefits one's own career from an objective perspective (e.g., hierarchical advancement and monetary rewards) (Collins, 1994; Liu, Liu, Kwan \& Mao, 2009; Bozionelos Bozionelos, Kostopoulos \& Polychroniou, 2011).
} 
guidance benefited protégés because it increased the frequency and speed of promotion.

Employment: Another objective measure of the success of career counseling and employment services is employee placement and employment rates. The following studies evaluated programs that integrated an element of career counseling into a larger career guidance and services program. For example, several studies have evaluated the British New Deal for Young People (NDYP), a welfare-to-work strategy that aims to help unemployed 18- to 24-year-olds find work and increase their employability. According to Reenen (2004), NDYP appears to have had a significant influence in moving more young people into jobs; young unemployed men are about $20 \%$ more likely to find jobs each month because of NDYP. Dorsett (2006) specifically examined the variety of employment strategies of NDYP. The first phase of NDYP is the Gateway stage, a period of intensive job search under the supervision of a caseworker. The second phase is the option stage where participants select one of four choices: (1) full-time subsidized employment; (2) full-time education or training; (3) work placement in a voluntary sector organization; or (4) work placement in an organization with an explicit environment-focus. Employing propensity score matching, Dorsett (2006) found that those that entered optional Phase 1 (fulltime subsidized employment) were most likely to find subsequent permanent employment. However, those who remained in the Gateway stage (intensive job search under the supervision of a caseworker) for a prolonged period were in fact more likely to find employment than those who entered the remaining Phase 2 options (full-time education or training, work in the voluntary sector, or work in the environmental sector).

Another study compared the effectiveness of employment services versus small-business assistance programs in helping the unemployed return to work (Rodriguez-Planas, 2007). For the purpose of this study, employment services included job clubs, job search courses, counseling, testing, and assessment, whereas small business assistance programs provide counseling and assistance in developing and implementing a business plan, and often included some form of financial assistance. Rodriguez-Planas (2007) found employment services to be more successful; in comparison to participating in small business assistance programs, participating in employment services increased the likelihood of being employed by 17.28 percentage points (or $34.18 \%$ ) for at least 12 months within the two-year period, and reduced the period of unemployment by over 3 months (or $27.48 \%$ ) during the same period.
Furthermore, a synthesis of evaluations of job search assistance programs including but not limited to job referrals, job counseling, skills assessment, job search training, resume writing, and interviewing techniques found that these programs had some positive effects on employment and earnings and were usually costeffective (Dar \& Tzannatos, 1999). However, the researchers cautiously noted that there appeared to be a positive correlation between the likelihood of success of job search assistance and local labor market conditions: programs that demonstrated successful results were situated in locations with more favorable economic conditions and lower unemployment rates.

Interestingly, Watts (2009) also found evidence in some countries of career counseling favoring general education at the expense of vocational education and training. Watts (2009) cited examples of studies across Australia and the United Kingdom where guidance practices served as a barrier to apprenticeship and VET participation by either limiting the availability of information or discouraging students from pursuing such paths. However, this might reflect the tendency for career guidance in formal education settings to be biased towards programs offered by their own institutions. Therefore, Watts (2009) underscored the importance of providing additional guidance from independent external agencies as offered in Germany and Switzerland. Further, for career guidance services to provide adequate information on VET programs, this requires revamping the training of career guidance practitioners as most career practitioners have not been trained within the VET system and therefore lack the knowledge and expertise to relay to students.

\section{Limitations and Implications}

It is difficult to draw general conclusions from these studies as the evidence is not strictly causal. In addition, the relevance and applicability of these studies is also tenuous as only a handful of studies focus on the student population, and of those only a few focus specifically on STEM (2004; Fouad, 1995; Kerr \& Robinson Kurpius; Stoeger et al., 2013). Based upon the available evidence, however, career counseling and employment services do seem to be effective in increasing subjective outcomes such as career initiative, career self-efficacy, and career satisfaction (Bernaud et al., 2006; Brennan, 2009; Chang \& Feng, 2014; Collins, 1994; Fouad, 1995; Gong et al., 2014; Kerr \& Robinson Kurpius, 2004; Pan et al., 20011; Perdix et al., 2013; Siebert, 1999; Stoeger et al., 2013; Wu et al., 
2013). However, the results of studies evaluating the impact of career counseling and employment services on increasing objective outcomes such as earnings, career advancement, or employment are mixed (Chang \& Feng, 2014; Collins, 1994; Dar \& Tzannatos, 1999; Dorsett, 2006; Gong et al., 2014; Reenen, 2004; Rodriguez-Planas, 2007; Watts, 2009). While most researchers found that counseling and employment services have a positive impact (Collins, 1994; Dar \& Tzannatos, 1999; Dorsett, 2006; Gong et al., 2014; Reenen, 2004; Rodriguez-Planas, 2007), a few report null (Chang \& Feng, 2014) or potentially negative consequences (Watts, 2009). In addition, Dar and Tzannatos (1999) highlight the important role that the economic context plays in determining the success of career counseling, and Watts (2009) underlines the need to overhaul the training of career guidance practitioners in order to ensure that they are not only knowledgeable of VET career pathways but also aware of the need to prioritize and promote VET.

\section{Monetary Incentives to Students}

\author{
Sherihan Khalil
}

This section explores the efficacy of monetary incentives (such as vouchers, scholarships, or cash transfers) to students to encourage attendance, reduce dropout rates, and increase enrollment in educational programs (particularly technical/ vocational education) and also to improve learning outcomes and post-secondary school aspirations. It includes a description of the literature as a whole, the relevant findings associated with this body of work, and any limitations or implications of these studies. While there have been very few studies on the role of monetary incentives in technical education specifically, we present the available evidence on the impact of monetary incentives in education more broadly, assuming that some of our findings may be applicable to technical education as well.

\section{Literature Description}

Sixteen studies dealing with the effects of monetary incentives to students are synthesized here. The following section provides an overview of the characteristics of the studies included in this synthesis.

Study Population. Of the 16 studies that examined the impact of monetary incentives to students, most targeted students currently attending either primary or secondary/vocational school. Further, many of these programs targeted very specific subgroups. For example, in Colombia, youth from the two lowest socioeconomic strata were targeted to receive vocational training vouchers (Attanasio et al., 2011), and in the Philippines, eligibility requirements for TVET scholarships included limits on family income, completion of high school, and completion of pretraining qualifications (Orbeta \& Abrigo, 2013).

Publication Type. Of these 16 studies, 11 are journal articles, and 5 are policy papers or reports.

Outcomes. Studies examined the impact of monetary incentives to students on an array of student outcomes including enrollment rates, attendance rates, dropout rates, grade progression, test scores, and the likelihood of taking a college entrance exam. 
Chapter Two | Provision of Information \& Incentives

Methodology. Thirteen of the 16 articles utilized a quasi-experimental or experimental design.

Region. In terms of regional scope, 2 papers were cross-regional or global in scope, 6 were based in Latin America, 5 in Asia, 1 in Africa, 1 in Europe, and 1 in the United States.

\section{Findings}

This section synthesizes the impact of monetary incentives on student outcomes such as student enrollment, attendance, and performance, as well as on earnings. The findings of these studies include several major topics: the impact of vouchers and subsidies; the impact of scholarships and fellowships; the impact of scholarships when performance is explicitly linked to the incentive; the impact of conditional cash transfers (CCTs); and the impact of incentives on female attendance and performance.

Impact of Vouchers and Subsidies: Attanasio et al. (2011) evaluated the Jovenes en Accion program in Colombia, which provided targeted VET training to poor urban youth, most of whom were high school dropouts. Among the many courses offered through local training institutes were those that trained students to become IT specialists, surveyors, or accountant assistants, among many other professions in administrative and manual occupations. The VET training totaled six months equally divided among classroom training and on-the-job training. Cash transfers to attend the program were administered to cover the cost of lunch and transportation, and women with children under seven years of age received higher cash transfers to accommodate childcare expenses. The impact evaluation of the program utilized a randomized experimental model to conclude that the women in the VET-trained treatment group benefited from increased earnings (increase of $19.6 \%$ ) and were more likely to find paid employment ( 0.068 higher probability), mainly from jobs in the formal sector.

Another experimental study in Colombia found additional benefits associated with the offer of vouchers to vocational schools. By comparing voucher lottery winners (who were allowed to select their school placement) to voucher lottery losers, Bettinger et al. (2010) concluded that the program yielded positive impacts on voucher winners' test scores and increased their likelihood of taking a college entrance exam, among other positive education outcomes. Although the peer groups selected by the voucher winners were lower in academic standing than the voucher losers, these positive education outcomes remained (Bettinger et al., 2010).

Impact of Scholarships and Fellowships: A randomized evaluation of a merit scholarship for girls in two districts of Kenya indicated an improvement in test scores by 0.19 standard deviations (for the "Intention to Treat" samples) (Kremer, Miguel, \& Thornton, 2009). The study also measured positive externalities within schools that offered the scholarship; the authors found that although the scholarships were targeted at girls alone, the schools that offered the scholarships saw an increase in boys' scores as well by 0.08 standard deviations.

The use of financial incentives for girls in low-income, urban neighborhoods of Quetta, Pakistan also showed a positive impact on primary school enrollment. A randomized impact evaluation of an Urban Girls' Fellowship Program found that the program increased enrollments by an average of $33 \%$ (Kim, Alderman, \& Orazema, 1998). The program differs from other financial incentives detailed here in that the subsidies for girls' enrollments were directly allocated to schools.

Additionally, Cameron (2000) analyzed the impact of a scholarship program offered to primary, lower secondary, and upper secondary school students during the Indonesian recession of the 1990s, and found that these financial incentives were positively associated with school attendance. Using both regression and propensity score matching to establish impact, the author also concluded that the scholarship program reduced dropout rates by $24 \%$ among students in lower secondary schools.

Further, in the Philippines, $73 \%$ of TVET graduates in 2007 received scholarships through either the Training for Work Scholarship Program or the Private Education Student Financial Assistance. The groups targeted to receive these scholarships were individuals that were classified as underemployed or unemployed. Incentives offered to individuals through these scholarships included the payment for all training, a stipend, a book allowance, career counseling, and employment referrals. In their non-experimental evaluation of these two scholarship programs, Orbeta and Abrigo (2013) show that the scholarships assisted in increasing TVET graduation rates yet did not assist in improving the employment rate of graduates. The study stated that the low employment rate was not a function of the scholarship programs but of broader sectoral constraints to employment. 
Impact of Financial Incentives on Student Performance when Performance is Incentivized: Numerous studies have found that providing a financial incentive that is contingent upon academic performance can be effective in increasing academic achievement or enrollment (Angrist, Bettinger, Bloom, King \& Kremer, 2002; Angrist, Bettinger, \& Kremer, 2006; Barrera-Osario \& Filmer, 2013; Behrman, Parker, Todd \& Wolpin, 2012; Fryer, 2011; Kremer et al., 2009; Leuven, Oosterbeek, \& van der Klaauw, 2003). For example, a randomized evaluation of merit-based scholarships in Kenya concluded that merit-based scholarships were the most costeffective way to boost students' primary school test scores when compared to other incentive schemes such as teacher incentive programs or book provision programs (Kremer et al., 2009). A Mexico-based randomized experiment on the effects of monetary incentives to improve mathematics achievement compared treatment effects of monetary incentives to mathematics exam performance between three treatments scenarios: when incentives were given to teachers only, students only, and teachers, students and administrators. The experiment concluded that largest gain in test scores were seen in schools in which students, teachers, and administrators received incentives, with gains also seen in schools in which only students received incentives; no significant gains, however, were seen in schools with teachers only receiving benefits (Behrman et al., 2012).

Further, a Cambodia-based RCT study comparing primary school and lower secondary school scholarships based on poverty level versus scholarships based on merit (higher test scores), found increased enrollments from both types of scholarships; however only the merit scholarships were associated with increased test scores (Barrera-Osario \& Filmer, 2013). Others have found incentive effects of smaller magnitude, as well as effects that are inconsistent across subjects or grades. For example, Fryer (2011) conducted a United States-based RCT and found that paying second grade students to read significantly improves students' reading achievement but has a detrimental impact on English language learners, and no impact on 9th graders.

Further, Angrist et al. (2002) conducted a study of Colombia's use of lotteries to distribute vouchers, which partially covered the cost of private secondary school for students who maintained satisfactory academic achievement. They found that voucher winners were not only about 10 percentage points more likely to finish 8th grade, but also scored 0.2 standard deviations higher on math and reading scores. Another study of Colombia's program also found that the vouchers increased high school graduation rates by 15-20\% (Angrist et al., 2006). At the tertiary school level, Leuven et al. (2003) conducted a randomized field experiment among first-year economics and business students at the University of Amsterdam to examine the effectiveness of financial incentives on student achievement when performance is incentivized. First-year students could earn financial rewards for passing first-year requirements in one year. They found that the financial incentives increased the achievement of high-ability students, but decreased the achievement of low-ability students.

Impact of CCTs: Though the literature on financial incentives in general may portray a positive to mixed review on the impact of financial incentives on student attendance, enrollment, and performance, the literature on conditional cash transfers in particular is largely positive in regards to attendance and enrollment (though not performance). The Rand Corporation's meta-analysis of 42 impact evaluations conducted in 15 developing countries in Latin America and Asia found that CCTs had a statistically significant impact on attendance for all age groups with the average effect much larger for secondary school students (a 12 percentage point impact for secondary school students versus a 3 percentage point increase for primary school students) (Saavedra \& Garcia, 2012). Secondly, the authors found that payment amount and payment frequency were critical factors influencing CCT impact: the more generous the $\mathrm{CCT}$, and the more frequent the payments, the larger the impact. Lastly, authors found that pay linked to achievement also increases impact.

In addition, Baird, Ferreira, Özler and Woolcook (2013) examined 11 studies on the use of both CCTs and UCT (unconditional cash transfers) and also found positive and significant effects of these programs on enrollment. Specific examples of these studies include an impact evaluation of the 1997 Progresa program in Mexico, which provided a positive appraisal of the provision of financial incentives to families, contingent upon children's regular school attendance. Progresa, which funds both primary and secondary school students, resulted in higher enrollments, quicker grade progression rates, and lower dropout rates (Behrman, Sengupta, \& Todd, 2005). Further, in Asia, Mo et al. (2013) conducted an RCT examining the role of CCTs in reducing drop out rates in rural China; they found that the dropout rate in the CCT group (5.3\%) was eight percentage points lower than in the control group (13.3\%). 
Impact of Financial Incentives on Females: Improvements in female attendance and/or performance are apparent in both programs that specifically target girls and programs that target both genders but contain gender-sensitive components. An example of the latter includes CCT programs such as Progresa in Mexico and a VET training to poor urban youth, Jovenes en Accion, in Colombia that provides financial incentives to both males and females for training and attendance. Although both programs target overall populations, their incentives structures are not gender neutral. For example, Progresa provides girls with higher financial incentives than boys (Behrman et al., 2005), and Jovenes en Accion provides women with children under the age of seven with higher cash transfers for childcare costs (Attanasio et al., 2011). With this set up, the impact on women's earnings and enrollment was significantly higher than boys or men (Behrman et al., 2005; Attanasio et al., 2011). Finally, in terms of female-specific programs, multiple impact evaluations indicated that these targeted incentive programs have positive effects on female school enrollment and attendance; examples include Cambodia (Filmer \& Schady 2008), Bangladesh (Raynor \& Wesson, 2006), Pakistan (Kim et al., 1998), and Kenya (Kremer et al., 2009).

\section{Limitations and Implications}

Based on the studies included in this synthesis, it appears that on average, financial incentives can increase attendance and enrollment (Kim et al., 1998; Cameron, 2000; Behrman et al., 2005; Filmer \& Schady, 2008; Kremer et al., 2009; Raynor \& Wesson, 2006; Saavedra \& Garcia, 2012; Barrera-Osario \& Filmer, 2013; Baird et al., 2013), grade progression (Cameron, 2000; Angrist et al., 2002; Behrman et al., 2005), graduation rates (Orbeta \& Abrigo et al., 2013; Angrist et al, 2006), academic performance (Angrist et al., 2002; Leuven et al., 2003; Kremer et al., 2009; Bettinger et al., 2010; Fryer, 2011; Barrera-Osario \& Filmer, 2013), and can also reduce dropout rates (Behrman et al., 2005; Mo et al., 2013). It is important to note that many of these programs targeted specific subgroups. Therefore, the effectiveness of financial incentives may not only vary by characteristics of the incentive-the amount and frequency-but also by characteristics of the recipients-school level, academic ability, English language status, and gender.

It is important to note that although most studies in this sample seem to report that financial incentives have a positive effect on student outcomes, only a few of these studies are specific to VET. Of the studies exploring the impact of vouchers and subsidies only two were VET-specific (Bettinger et al., 2010; Attanasio et al., 2011), and of those exploring the impact of scholarships or fellowships, only one was VET-specific (Orbeta \& Abrigo, 2013). Thus while these incentives certainly have the potential to improve educational outcomes in the field of technical education as well, the current state of the evidence-base does not yet allow for such definitive conclusions. 
Strategies for

Strengthening

the Technical

Workforce 

non-governmental organizations, technical schools, and industries. Although this synthesis is to an extent limited by the availability of rigorous impact evaluations, the studies considered here do still offer policy recommendations for each of the five strategies used to address the need for skills development: vocational education, apprenticeships, cooperative education, career academies, and e-learning programs.

Vocational education. Based on the impact evaluations considered in this literature review, there are several recommendations we propose for vocational education programs. First, the literature suggests that the tighter the link between vocational education programs and industries or firms, the more successful the intervention. For labor market training programs, for example, industries could use company-based vocational training programs as a means of recruiting future employees. Second, high quality labor market training institutions had a much greater impact on students, thus any government or private sectorfunded vocational education initiative should employ a competitive bidding process in choosing vocational programs to support. This process should consider factors including but not limited to the legal status (formality) of the program; the level of human resources and infrastructure or resources supporting the program; the appropriateness of coursework/curricular structure given the labor demand; and the expenditures per trainee. Third, if the organization in charge of implementing the vocational education program also functioned as a job placement and counseling organization, this could be an efficient way to track students and ensure their success. Lastly, policymakers should consider focusing on untapped markets. Preliminary evidence suggests that some private vocational schools may be more equipped to adjust to changing market demands than their public counterparts. Moreover, programs should target women to participate since studies suggest that women consistently seem to benefit more from vocational training than their male counterparts but are also less likely to sign up for vocational training (particularly the type of vocational training with high returns such as training in traditionally male-dominated trades). 
Apprenticeships. Apart from a randomized study of a national apprenticeship program in Ghana which is currently underway (Lehrer, Mbiti, \& McCasland, 2014), the rigorous efficacy literature on apprenticeship programs is limited to Europe, making it difficult to draw inferences from these studies to other contexts. However, within the European system, there are several summative findings. Apprenticeship trainings were linked to positive income returns in the short run, though in the long run these returns may decline; shorter unemployment spells (compared to unskilled workers); and an increased probability of finding immediate employment (postapprenticeship). However, when compared to individuals who have completed secondary education or VET, the results for apprenticeship training were more mixed. There was also variation in the returns of apprenticeships based on student characteristics. For example, returns were higher for men (given that women were more likely to have completed apprenticeships in more female-dominated, lowwage sectors), for students with high quality education credentials, and for those that complete more "intense" or prestigious apprenticeships.

Cooperative education. Only a few studies of cooperative education programs used experimental or quasi-experimental methods, so any differences between participants and non-participants may not be fully attributable to these cooperative education programs alone. Additionally, several of these studies employed only self-reported data. Nonetheless, based on the studies included in this literature review, it seems that cooperative education appears to have high potential for connecting school experience with the workplace and for keeping students in school. A number of the studies found that students who completed cooperative education programs received higher starting salaries and spent less time finding a first job placement compared to non-cooperative education students. Furthermore, student responses to program surveys offered several recommendations for improving cooperative education programs, such as offering guidance about industries in which students could be placed for work, providing continuous mentoring by adults while working, and implementing high-quality transition programs.

Career academies. While several studies found career academies to be associated with positive education outcomes (in terms of school attendance, credits earned toward high school graduation, grade point average, and retention through high school), the most rigorous study of career academies (a randomized trial), conducted by MDRC, found a great degree of heterogeneity in impact, depending on the particular school and program. Further, these studies indicated that though career academy enrollment was associated with higher graduation rates, the impact on student dropout rates was mixed, except in the case of high-risk students where the program seems to have had higher positive impacts overall. And while the results on tertiary education aspirations, admissions, and enrollment are more mixed, career academy students were provided with more labor market preparation and also tended to earn more than non-academy students in the labor market, with impacts slightly higher among young men.

\section{Workforce training through e-learning. Overall the} research and policy literature on e-learning training indicate that the success of e-learning programs in post-secondary populations is not significantly different from face-to-face programs. However, certain studies indicate that these programs may be less effective for low-income students, while at the same time more effective for students performing at both particularly high and low levels, due to the ability of these programs to target the particular learning needs of students The evidence also indicates that blended learning, which is instructor-led and collaborative, is more effective than fully online, independent learning, particularly when blended learning is accompanied by extensive practice and instructor feedback. There is also a substantial amount of policy literature which highlights the potential for e-learning to completely transform the technical workforce. However, this literature also highlights the need for ICT skills development in the student and teacher population overall as a precursor to workforce e-learning, as well as the need for investments in training time (among employers) and an e-learning infrastructure at both the country and industry-level.

In addition to the strategies outlined above to strengthen preparation for technical employment, the overall access people have to information and incentives related to participating in a technical program also needs to be improved. While only a few studies address the efficacy of strategies used to increase accessibility to information and incentives-informational interventions, career counseling coupled with employment services, and monetary incentives - the available research still provide several noteworthy suggestions and underscore areas that require further investigation.

Information interventions. The limited sample of impact evaluations in this review found that informing students of the returns associated with various levels of education was effective in influencing school choice. Further, the more individuals' misperceptions of these returns differ from reality, the more impactful an intervention can be. For example, in countries where individuals had overly optimistic perceptions of the rate of return to vocational education, informational interventions had no statistically significant impact on student demand for vocational education. Contrastingly, where the rate of return to education was perceived as lower than its real value, informational interventions had a positive impact on schooling attainment. In addition to ensuring that people have an accurate perception of the returns of vocational education, counseling and guidance about the options open to adults (as well as the returns on those options) and assistance with filling 
out complicated forms, may generate an even larger impact on individual choices.

Career counseling and employment services. The limited available evidence suggests that career counseling and employment services are effective in increasing subjective outcomes such as career initiative, career self-efficacy, career commitment, and career satisfaction. However, the studies revealed mixed results on the association between career counseling and increasing objective outcomes such as earnings, career advancement, or employment; while most researchers found that counseling and employment services have a positive impact on these factors, a few reported null findings, which were partially driven by local economic conditions.

Monetary incentives to students. According to the studies included in this synthesis, on average, financial incentives increase attendance and enrollment, grade progression, graduation rates, and academic performance, and can also reduce dropout rates. However, since many incentive programs target specific groups, their effectiveness may vary both by characteristics of the incentive (the amount and frequency) and by characteristics of the recipients (school level, academic ability, English language status, and gender). Furthermore, while financial incentives certainly have the potential to improve education outcomes, only a few of these studies were specific to vocation or technical education, thus we cannot yet draw definitive conclusions about the impact of these incentives on VET enrollment, subsequent education, or labor market outcomes.

The research evidence synthesized here indicates that there is overall a high potential to improve the technical skills of the workforce through vocational education, apprenticeships, cooperative education, career academies, and e-learning programs. However, the extent to which each of these strategies is successful varies based on a variety of factors, including the country context, the duration/completion of the program, the availability of support systems, the background of participants, etc. Equally important to this discussion is the accessibility of information about and incentives for partaking in the aforementioned programs, whether it is through information interventions, career counseling and employment services, and/or monetary incentives to students. Similar to the program strategies, the effectiveness of each of these strategies to increase accessibility also varies by context. Nonetheless, the available evidence suggests that policies and practices that promote skill-development programs and the accessibility of information and incentives would encourage the growth of the technical workforce. 


\section{References}

Acemoglu, D., \& Pischke, J. S. (1998). Why do firms train? Theory and evidence. The Quarterly Journal of Economics, 113(1): 79-119.

Adda, J., Dustmann, C., Meghir, C., \& Robin, J. M. (2010). Career progression and formal versus on-the-job training (Working Paper No. 2260). Retrieved from Institute for the Study of Labor website: http://ftp.iza.org/dp2260.pdf

Aedo, C., \& Nunez, S. (2003). The impact of training policies in Latin America and the Caribbean: The case of Programa Joven (Working Paper No. R0483). Retrieved from Inter-American Development Bank website: http://publications.iadb.org/bitstream/ handle/11319/3287/The\%20Impact\%20of\%20 Training\%20Policies\%20in\%20Latin\%20America\%20 and\%20the\%20 Caribbean\%3a\%20The\%20Case\%20 of\%20Programa\%20 Joven.f;jsessionid=F5E3980594958C3842BCB229903CC4C7? sequence $=1$

Allen, T. D., Eby, L. T., Poteet, M. L., Lentz, E., \& Lima, L. (2004). Career benefits associated with mentoring for protégés: A meta-analysis. Journal of Applied Psychology, 89(1): 127-136.

Alzuá, M. L., \& Brassiolo, P. (2006). The impact of training policies in Argentina: an evaluation of Proyecto Joven (Working Paper No. OVE/WP-15/06). Retrieved from InterAmerican Development Bank website: http://idbdocs. iadb.org/wsdocs/getdocument.aspx? docnum=936639

Alzúa, M. L., Nahirñak, P., \& Alvarez de Toledo, B. (2007). Evaluation of entra 21 using quantitative and qualitative data (Working Paper No. 41). Retrieved from Instituto de Estudios sobre la Realidad Argentina y Latinoamericana (IERAL) website: http://www.ieral.org/images_db/ noticias_archivos/3597-280429870.pdf

Angrist, J., Bettinger, E., Bloom, E., King, E., \& Kremer, M. (2002). Vouchers for private schooling in Colombia: Evidence from randomized natural experiments. American Economic Review, 92(5): 1535-1558.

Angrist, J., Bettinger, E., \& Kremer, M. (2006). Long-term consequences of secondary school vouchers: Evidence from administrative records in Colombia. American Economic Review, 96(3): 847-862.

Athanasou, J. A., \& van Esbroeck, R. (Eds.). (2008). International Handbook of Career Guidance. Dordrecht, Netherlands: Springer.
Attanasio, O., Kugler, A., \& Meghir, C. (2011). Subsidizing vocational training for disadvantaged youth in Colombia: Evidence from a randomized trial. American Economic Journal: Applied Economics, 3(3): 188-220.

Avenoso, E., \& Totoro, K.C. (1994). Comparison of retention rates of first and second year coop and noncoop students at a small liberal arts college. Journal of Cooperative Education, 29(1): 6-13.

Baird, S., Ferreira, F. H. G., Özler, B., \& Woolcock, M. (2013). Relative effectiveness of conditional and unconditional cash transfers for schooling outcomes in developing countries: A systematic review. Campbell Systematic Reviews 2013, 8: 1-124.

Barrera-Osorio, F., \& Filmer, D. (2013). Incentivizing schooling for learning: Evidence on the impact of alternative targeting approaches (Working Paper No. 6541). Retrieved from the World Bank website: http://documents.worldbank.org/curated/ en/2013/07/18029267/incentivizing-schooling-learningevidence-impact-alternative-targeting-approaches

Bartlett, K. R. (2002). The perceived influence of industrysponsored credentials in the information technology industry. Retrieved from United States Government Publishing Office website: http://www.gpo.gov/fdsys/ pkg/ERIC-ED465072/pdf/ERIC-ED465072.pdf

Bartlett, K. R., Horowitz, S. K., Ipe, M., \& Liu, Y. (2005). The perceived influence of industry-sponsored credentials on the recruitment process in the information technology industry: Employer and employee perspectives. Journal of Career and Technical Education, 21 (2).

Bedwell, W. L., \& Salas, E. (2010). Computer-based training: Capitalizing on lessons learned. International Journal of Training and Development, 14(3): 239-249.

Bello, G., Pennisi, M. A., Maviglia, R., Maggiore, S. M., Bocci, M. G., Montini, L., \& Antonelli, M. (2005). Online vs. live methods for teaching difficult airway management to anesthesiology residents. Intensive Care Medicine, 31 (4): 547-552.

Benjamin, S. E., Tate, D. F., Bangdiwala, S. I., Neelon, B. H., Ammerman, A. S., Dodds, J. M., \& Ward, D.S. (2008). Preparing child care health consultants to address childhood overweight: A randomized controlled trial comparing Web to in-person training. Maternal and Child Health Journal, 12(5): 662-669.

Benson, A. D., Johnson, S. D., Taylor, G. D., Treat, T., Shinkareva, O. N., \& Duncan, J. (2004). Distance learning in postsecondary career and technical education: A comparison of achievement in online vs. on-campus 
CTE courses. St. Paul, MN: National Research Center for Career and Technical Education.

Behrman, J. R., Parker, S. W., Todd, P. E., \& Wolpin, K. I. (2012). Aligning learning incentives of students and teachers: Results from a social experiment in Mexican high schools (Working Paper 13-004). Retrieved from Penn Institute for Economic Research, University of Pennsylvania website: http://economics.sas.upenn.edu/ system/files/13-004.pdf

Behrman, J. R., Sengupta, P., \& Todd, P. (2005). Progressing through PROGRESA: An impact assessment of a school subsidy experiment in rural Mexico. Economic Development \& Cultural Change, 54(1): 237-275.

Bennett, J. V. (2007). Work-based learning and social support: relative influences on high school seniors' occupational engagement orientations. Career and Technical Education Research, 32(3): 187-214.

Bernaud, J. L., Gaudron, J. P., \& Lemoine, C. (2006). Effects of career counseling on French adults: An experimental study. The Career Development Quarterly, 54(3): 242-255.

Bertschy, K., Cattaneo, M. A., \& Wolter, S.C. (2009). PISA and the transition into the labour market. Labour, 23(1): $111-137$.

Betcherman, G., Dar, A., Luinstra, A., \& Ogawa, M. (2000). Active Labor Market Programs: Policy Issues for East Asia (Working Paper No. 005). Retrieved from the World Bank website: http://documents.worldbank. org/curated/en/2000/01/717471/active-labor-marketprograms-policy-issues-east-asia.

Bettinger, E., Kremer, M., \& Saavedra, J. E. (2010). Are educational vouchers only redistributive? Economic Journal, 120(546): F204 - F228.

Bettinger, E. P., Long, B. T., Oreopoulos, P., \& Sanbonmatsu, L. (2012). The role of application assistance and information in college decisions: Results from the H\&R Block FAFSA experiment. The Quarterly Journal of Economics, 127(3): 1205-1242.

Beyea, J. A., E. Wong, M. Bromwich, W. W. Weston, \& K. Fung. (2008). Evaluation of a particle repositioning maneuver web-based teaching module. The Laryngoscope 118(1): 175-180.

Bishop, J. (1996). What we know about employer provided training: A review of the literature (Working Paper No. 96-09). Retrieved from Cornell University, School of Industrial and Labor Relations, Center for
Advanced Human Resource Studies website: http:// digitalcommons.ilr.cornell.edu/cahrswp/180 Blair, B. F., \& Millea, M. (2004a). Quantifying the benefits of cooperative education. Journal of Cooperative Education \& Internships, 38(1): 67-72.

Blair, B. F., \& Millea, M. (2004b). Student academic performance and compensation: The impact of cooperative education. College Student Journal, 38(4): 643-652.

Blair, B.F., Millea, M., \& Hammer, J. (2004). The impact of cooperative education on academic performance and compensation of engineering majors. Journal of Engineering Education, 93(4), 333-338.

Bonnal, L., Mendes, S., \& Sofer, C. (2002). School-to-work transition: Apprenticeship versus vocational school in France. International Journal of Manpower, 23(5): 426442.

Bougheas, S., \& Georgellis, Y. (2004). Early career mobility and earnings profiles of German apprentices: Theory and empirical evidence. Labour, 18(2): 233- 263.

Brennan, M. D. (2009). The effect of career assessment and follow-up counseling on career decision-making self-efficacy (CDMSE) among active-duty coast guard personnel (Doctoral dissertation). Retrieved from ProQuest.

Brunello, G. (2009). The effect of economic downturns on apprenticeships and initial workplace training: A review of the evidence. Paris, France: OECD.

Buchel, F. (2002). Successful Apprenticeship-to-work Transitions: On the long-term change in significance of the German school-leaving certificate. International Journal of Manpower. 23(5): 394-410.

Caliendo, M., Künn, S., \& Schmidl, R. (2011) Fighting youth unemployment: The effects of active labor market policies (Working Paper No. 6222). Retrieved from Institute for the Study of Labor website: http://ftp.iza.org/ dp6222.pdf

Cameron, L. A. (2000). An analysis of the role of social safety net Scholarships in reducing school drop-out during the Indonesian economic crisis (Working Paper No. 82). Retrieved from UNICEF Innocenti Research Centre website: http://www.unicef-irc.org/publications/ pdf/iwp82.pdf

Cappellari, L., Dell'Aringa, C., \& Leonardi, M., (2012). Temporary employment, job flows and productivity: A 
tale of two reforms. The Economic Journal, 122(562): 188215.

Card, D., Ibarraran, P., Regalia, F., Rosas, D., \& Soares, Y. (2011). The labor market impacts of youth training in the Dominican Republic. Journal of Labor Economics, 29(2): 267-300.

Card, D., Kluve, J., \& Weber, A. (2009). Active labor market policy evaluations: A meta-analysis (Working Paper No. 4002). Retrieved from Institute for the Study of Labor website: http://ftp.iza.org/dp4002.pdf

Castellano, M., Stone, J.R., Stringfield, S., FarleyRipple, E.N., \& Overman, L.T. (2007). Career-based comprehensive school reform: Serving disadvantaged youth in minority communities. St. Paul, MN: National Research Center for Career and Technical Education.

Castellano, M., Sundell, K., Overman, L., \& Aliaga, O. (2011). Rigorous tests of student outcomes in CTE programs of study: Year 3 report. St. Paul, MN: National Research Center for Career and Technical Education.

Cedefop - European Centre for the Development of Vocational Training. (2012). Loans for vocational education and training in Europe (Working Paper No. 20). Luxembourg: Publications Office from the European Union.

Chanchalor, S., \& Kammeungmai, D. (2011). Vocational students in Thailand: Collaborative learning via the internet in groups of different sizes. Global Journal of Engineering Education, 13(2): 64-69.

Chang, H.T., \& Feng, C.Y. (2014). Individual management and counseling as moderators in achieving career competencies and success. Social Behavior and Personality, 42(5): 869-880.

Chinien, C. (2003). The use of ICTs in echnical and Vocational Education and Training: Analytical survey. MOscow, Russia: UNESCO Institute for Information Technologies in Education.

Chinien, C. (2005). ICT application in Technical and Vocational Education and Training: Specialized training course. Moscow, Russia: UNESCO Institute for Information Technologies in Education.

Chong, A., \& Galdo, J. (2006). Does the quality of training programs matter? Evidence from bidding processes data (Working Paper No. 2202). Retrieved from Institute for the Study of Labor website: http://ftp.iza.org/ dp2202.pdf
Chun, N., \& Watanabe, M. (2011). Can skill diversification improve welfare in rural areas? Evidence from the rural skills development project in Bhutan (Working Paper Series No. 260). Retrieve from Asian Development Bank website: http://www.adb.org/publications/can-skilldiversification-improve-welfare-rural-areas-evidencerural-skills-development

Clark, R.C., \& Mayer, R. E. (2013). Scenario-based e-learning: Evidence-based guidelines for online learning. San Francisco, CA: John Wiley \& Sons.

Clark, D., \& Fahr, R. (2002). The promise of workplace training for non-college bound youth: Theory and evidence from German apprenticeship (Working Paper No. 518). Retrieved from Centre for Economic Performance website: http://cep.Ise.ac.uk/pubs/ download/dp0518.pdf

Collins, P.M. (1994). Does mentorship among social workers make a difference? An empirical investigation of career outcomes. Social Work, 39(4): 413-419.

Cooperative Education \& Internship Association (CEIA). (n.d.). History - Cooperative Education and Internships. Retrieved from Cooperative Education \& Internship Association website: http://www.ceiainc.org/history

Curtain, R. (2002). Online delivery in the vocational education and training sector: Improving cost effectiveness. Leabrook, Australia: National Centre for Vocational Education Research.

Dar, A., \& Tzannatos, Z. (1999). Active labor market programs: A review of the evidence from evaluations (Working Paper No. 9901). Retrieved from the World Bank website: http://www-wds.worldbank.org/external/ default/WDSContentServer/WDSP/IB/2000/04/19/0000949 46_00040502394113/Rendered/PDF/multi_page.pdf

Darch, J. (1995). Labour market outcomes for university co-op graduates. Perspectives on Labour and Income, $7(3): 20-24$.

Day, T. M., Raven, M. R., \& Newman, M. E. (1998). The effects of World Wide Web instruction and traditional instruction and learning styles on achievement and changes in student attitudes in a technical writing in agricommunication course. Journal of Agricultural Education, 39(4): 65-75

Delajara, M., Freije, S., \& Soloaga, I. (2006). An evaluation of training for the unemployed in Mexico (Working Paper No. OVE/WP-09/06). Retrieved from Inter-American Development Bank website: http://idbdocs.iadb.org/ wsdocs/getdocument.aspx? docnum $=907641$ 
Díaz, J. J., \& Jaramillo, M. (2006). An evaluation of the Peruvian 'Youth Labor Training Program' - Projoven (Working Paper No. OVE/WP-10/06). Retrieved from Inter-American Development Bank website: http:// publications.iadb.org/bitstream/handle/11319/3000/ AN\%20EVALUATION\%20OF\%20THE\%20PERUVIAN\%20 ¿YOUTH\%20LABOR\%20TRAINING\%20PROGRAM $\%$ 20-\%20 PROJOVEN.pdf? sequence=1

Dionisius, R., Mühlemann, S., Pfeifer, H., Walden, G., Wenzelmann, F., \& Wolter, S.C. (2009) Costs and benefits of apprenticeship training: A comparison of Germany and Switzerland. Applied Economics Quarterly, 55(1): 5-38.

Dmitrijeva, J. (2009). The employment effects of public training programme: Evidence from Latvian micro and macro data. Retrieved from Université d'Orléans website: http://citeseerx.ist.psu.edu/viewdoc/ summary? doi=10.1.1.404.3441

Dorsett, R. (2006). The new deal for young people: Effect on the labour market status of young men. Labor Economics, 13(3): 405-422.

Dubick, R. A., McNerney, R. B., \& Potts, B. K. (1996). Career success and student satisfaction: A study of computer science cooperative education graduates. Journal of Cooperative Education, 32(1): 66-74.

Dunn, R. L. (2003). Getting into e-learning for workforce training. Plant Engineering Magazine. Retrieved from Control Engineering website: http://www.controleng. com/single-article/getting-into-e-learning-for-workforcetraining/fd0897858830c8302ba4f3d2fb793dc4.html

Eby, L. T., Allen, T. D., Evans, S. C., Ng, T., \& DuBois, D. L. (2008). Does mentoring matter? A multidisciplinary meta-analysis comparing mentored and non-mentored individuals. Journal of Vocational Behavior, 72(2): 254267.

El-Deghaidy, H., \& Nouby A. (2008). Effectiveness of a blended e-learning cooperative approach in an Egyptian teacher education programme. Computers \& Education, 51 (3): 988- 1006.

Euwals, R., \& Winkelmann, R. (2004). Training intensity and first labour market outcomes of apprenticeship graduates. International Journal of Manpower, 25(5): 447-462.

Fersterer, J., Pischke, J. S., \& Winter-Ebmer, R. (2008). Returns to apprenticeship training in Austria: Evidence from failed firms. Scandinavian Journal of Economics, $110(4):$ 733-753.
Field, S., Hoeckel, K., Kis, V., \& Kuczera, M. (2010). Learning for Jobs: OECD reviews of vocational education and training initial report. Paris, France: OECD

Filmer, D., \& Schady, N. (2006). Getting girls into school: Evidence from a scholarship program in Cambodia (Working Paper No. 3910). Retrieved from the World Bank website: http://www-wds.worldbank.org/servlet/ WDSContentServer/WDSP/IB/2007/1 1/28/000158349_2007 $1128084228 /$ Rendered/PDF/wps3910.pdf

Fouad, N. A. (1995). Career linking: An intervention to promote math and science career awareness. Journal of Counseling and Development, 73(5): 527-34.

Frederickson, N., Reed, P., \& Clifford, V. (2005). Evaluating web-supported learning versus lecture-based teaching: Quantitative and qualitative perspectives. Higher Education 50(4): 645-664.

Fryer, R. G. (2011). Financial incentives and student achievement: Evidence from randomized trials. Quarterly Journal of Economics, 126(4): 1755-1798.

Garavan, T. N., \& Murphy, C. (2001). The cooperative education process and organisational socialisation: A qualitative study of student perceptions of its effectiveness. Education \& Training, 43(6): 281-302.

Gemici, S., \& Rojewski, J. W. (2010). Contributions of cooperative education in preparing at-risk students for post-high school transition. Journal of Education for Students Placed at Risk, 15(3): 241-258

German Missions in the United States. The German vocational training system: An overview. Retrieved 12 September 2014, from http://www.germany.info/ Vertretung/usa/en/06_Foreign__Policy_state/02_ Foreign__Policy/05__KeyPoints/Vocational__Training.html

Gill, I. S., Dar, A., \& Fluitman, F. (1999). Constraints and innovation in reforming national training systems - crosscountry comparisons. International Journal of Manpower, 20(7): 405-431.

Gilliver, R. S., Randall, B., \& Pok, Y. M. (1998). Learning in cyberspace: Shaping the future. Journal of Computer Assisted Learning 14(3): 212-22.

Githens, R. P., Saver, T. M., Crawford, F. L., \& Wilson, K. B. (2012). Online occupational education in community colleges: Prevalence, programming, and connection with workforce development needs. Career and Technical Education Research, 37(1): 35-56. 
Goertz, L., \& Johanning, A. (2004). E-learning for small and medium-sized enterprises and public administrations: A guide for successful employment and development of modern e-learning solutions (Document No. 540). Wernigerode, Germany: Federal Ministry of Economics and Labour.

Goggel, K., \& Zwick, T. (2012). Heterogeneous wage effects of apprenticeship training. Scandinavian Journal of Economics, 114(3): 756-779.

Goho, J., \& Rew, D. (2009). Effects of cooperative education on community college employment outcomes at the school to work transition. Journal of Applied Research in the Community College, 16(2): 8391.

Gong, R., Chen, S. Y., \& Yang, M. L. (2014). Career outcome of employees: the mediating effect of mentoring. Social Behavior and Personality, 42(3): 487502.

Granger, B. P., \& Levine, E. L. (2010). The perplexing role of learner control in e-learning: will learning and transfer benefit or suffer? International Journal of Training and Development, 14(3): 180-197.

Groh, M., Krishnan, N., McKenzie, D., \& Vishwanath, T. (2012). Soft skills or hard cash? The impact of training and wage subsidy programs on female youth employment in Jordan (Working Paper No. 6141). Retrieved from the World Bank website: http://documents.worldbank.org/ curated/en/2012/07/16530040/soft-skills-or-hard-cashimpact-training-wage-subsidy-programs-female-youthemployment-jordan

Groot, W. J. N., \& Plug, E. (1998). Apprenticeship versus vocational education: Exemplified by the Dutch situation (Working paper TSER/STT, No. WP 10-98). Orléans, France: Faculté de Droit, d'Économie et de Gestion d'Orleans.

Hairston, N., \& Nafukho, F. M. (2011). Determining statistical significance between e-learning training versus traditional training in six different industry settings. International Journal of Vocational Education and Training, 19(1): 7-22.

Hamalainen, K., \& Ollikainen, V. (2014). Differential effect of active labour market programmes in the early stages of young people's unemployment (VATT Research Report No. 115). Helsinki: Government Institute for Economic Research.

Hardoy, I. (2005). Impact of multiple labour market programmes on multiple outcomes: The case of Norwegian youth programmes. Labour, 19(3): 425-467.
Harris, J. M., Elliott, T. E., Davis, B. E., Chabal, C., Fulginiti, J.V., \& Fine, P.G. (2007). Educating generalist physicians about chronic pain: Live experts and online education can provide durable benefits. Pain Medicine 9(5): 555-63.

Hashim, J. (2008). Factors influencing the acceptance of web-based training in Malaysia: applying the technology acceptance model. International Journal of Training and Development, 12(4): 253-264.

Hastings, J. S., \& Weinstein, J. M. (2008). Information, school choice, and academic achievement: Evidence from two experiments. Quarterly Journal of Economics, 123(4): 1373-1414.

Heidel, J., Ali, H., Corbett, B., Liu, J., Morrison, B., O'Connor, M., Richter-Egger, D., \& Ryan, C. Increasing the number of homegrown STEM majors: What works and what doesn't. Science Educator, 20(1): 49-54.

Hicks, J. H., Kremer, M., Mbiti, I., \& Miguel, E. (2011). Vocational education voucher delivery and labor market returns: a randomized evaluation among Kenyan youth (Report for Spanish Impact Evaluation Fund (SIEF) Phase II). Washington, DC: the World Bank.

Higgins J.P.T., \& Green, S. (Eds). (2011). Cochrane Handbook for Systematic Reviews of Interventions Version 5.1.0. The Cochrane Collaboration. Available from www. handbook.cochrane.org.

Hirshleifers, S., McKenzie, D., Almeida R., \& RidaoCano, C. (2004). The Impact of vocational training for the unemployed: Experimental evidence from Turkey (Working Paper No. 6807). Retrieved from the World Bank website: http://documents.worldbank.org/curated/ en/2014/03/19258767/impact-vocational-trainingunemployed-experimental-evidence-turkey

Hofer, H. \& Lietz, C. (2004). Labour market effects of apprenticeship training in Austria. International Journal of Manpower, 25(1): 104-122.

Hugenholtz, N. I. R., de Croon, E. M., Smits, P. B., van Dijk, F. J. H., \& Nieuwenhuijsen, K. (2008). Effectiveness of e-learning in continuing medical education for occupational physicians. Occupational Medicine, 58(5): 370-72.

Hughes, K. L., Bailey, T. R., \& Mechur, M. J. (2001). Schoolto-Work: Making a difference in education. A research report to America. Retrieved from Teachers College, Columbia University website: http://www.tc.columbia. edu/iee/PAPERS/Stw.pdf 
Huttunen, K., Pirttila, J., \& Uusitalo, R. (2010). The employment effects of low-wage subsidies (Working Paper No. 3043). Munich, Germany: CESifo Group.

Ibarraran, P., \& Rosas-Shady, D. (2006). Impact evaluation of the job training component (PROCAJOVEN) of the assistance program for the building of a training and employment system in Panama (PNO 125) (Ex-Post Project Evaluation Report No. OVE/EPPER-02/06). Washington, DC: Inter-American Development Bank.

Ibarraran, P., Ripani, L., Taboada, B, Villa, J. M., \& Garcia, B. (2014). Life skills, employability and training for disadvantaged youth: Evidence from a randomized evaluation design. Journal of Labor \& Development, $3(10)$.

Inayat, I., ul Amin, R., Inayat, Z., \& Salim, S.S. (2013). Effects of collaborative web based Vocational Education and Training (VET) on learning outcomes. Computers \& Education, 68: 153-166.

Information-Technology Promotion Agency. (n.d.). IT human resources development. Retrieved from Information-technology Promotion Agency website: http://www.ipa.go.jp/english/humandev/index.html

Jaeger, A. J., Eagan, M. K., \& Wirt, L. G. (2008). Retaining students in science, math, and engineering majors: Rediscovering cooperative education. Journal of Cooperative Education and Internships, 42(1): 20-32.

Jaggars, S.S., \& Bailey, T. (2010). Effectiveness of fully online courses for college students: response to a Department of Education meta-analysis (Working Paper). New York: Community College Research Center, Teachers College, Columbia University.

Jaramillo, M., Galdo, J., \& Montalva, V. (2007). Do the poorest among the poor benefit less from active labor market programs? Evidence from Perus' Projoven. Final Report, Presented to the Poverty and Economic Policy Network PEP-NET, PMMA Subnetwork.

Jensen, R. (2010). The (perceived) returns to education and the demand for schooling. The Quarterly Journal of Economics, 125(2): 515-548

Jinnah, M. A., Al-Mamum, A., Khan, S. H., \& Hasan, M. (2011). ICT in vocational teaching/learning and research in Southeast Asian Countries: A case of Bangladesh. International Journal of Vocational and Technical Education, 3(2): 20-28.
Jones, N., \& Fitzgibbon, K. (2002). For better or worse? The marriage of key skills development and on-line learning. Journal of Vocational Education \& Training, 54(3): 395-411.

Kane, T. J., \& Avery, C. (2004). Student perceptions of college opportunities: The BostonCOACH Program, In C. Hoxby (ed.), College Choices: The Economics of Where to Go, When to Go, and How to Pay for It. Chicago: University of Chicago Press.

Karaali, D., Gumussoy, C. A., \& Calisir, F. (2011). Factors affecting the intention to use a web-based learning system among blue-collar workers in the automotive industry. Computers in Human Behavior, 27(1): 343-354.

Kasipar, C., Tien, M. V., Lim, S.Y., Phuong, P. L., Huy, P. Q., Schnarr, A... \& Bunning, F. (2009). Linking vocational training with the enterprises - Asian perspectives.

Germany: InWEnt - Capacity Building International.

Kemple, J. (1997). Career academies: Communities of support for students and teachers-Emerging findings from a 10-site evaluation. New York, NY: MDRC.

Kemple, J. (2001). Career Academies: Impacts on students' initial transitions to post-secondary education and employment. New York, NY: MDRC.

Kemple, J. (2004). Impacts on labor market outcomes and education attainment. New York: MDRC.

Kemple, J. (2008). Career academies long-term impact on labor market outcomes, education attainment, and transitions to adulthood. New York, NY: MDRC.

Kemple, J., \& Snipes, J. (2000).Career academies: Impacts on students' engagement and performance in High School. New York, NY: MDRC.

Kerr, B., \& Robinson Kurpius, S. E. (2004). Encouraging talented girls in math and science: effects of a guidance intervention. High Ability Studies, 15(1): 85-102.

Kim, J., Alderman, H., \& Orazema P. (1998). Can private schools subsidies increase schooling for the poor? The Quetta Urban Fellowship Program. The World Bank Economic Review, 13(3): 443-465.

Kluve, J. (2010). The effectiveness of European active labor market programs. Labour Economics, 17(6): 904918. 
Koffarnus, M.N., Defulio A., Sigurdsson, S., \& Silverman, K. (2013). Performance pay improves engagement, progress, and satisfaction in computer based job skills training of low-income adults. Journal Of Applied Behavior Analysis, 46(2): 395-406.

Koffarnus, M.N., Wong, C.J., Fingerhood, M., Svikis, D.S., Bigelow, G.E., \& Silverman, K. (2013). Monetary incentives to reinforce engagement and acheivement in a job skills training program for homeless, unemployed adults. Journal Of Applied Behavior Analysis, 46(3): 582-591.

Kostøl, A. R., \& Mogstad M. (2014). How financial incentives induce disability insurance recipients to return to work. American Economic Review, 104(2): 624-655.

Kramarz, F., \& Philippon, T. (2001). The impact of differential payroll tax subsidies on minimum wage employment. Journal of Public Economics, 82(1): 115-14.

Kremer, M., Miguel, E., \& Thornton, R. (2009). Incentives to learn. Review Of Economics And Statistics, 91 (3): 437-456.

Kuddo, A. (2009). Labor Laws in Eastern European and Central Asian Countries: Minimum Norms and Practices. The World Bank Social Protection \& Labor Discussion (Discussion Paper No. 0920).

Kuruvilla, S., Erickson, C., \& Huand, A. (2002). An assessment of the Singapore Skills Development System: Does it constitute a viable model for other developing countries? World Development, 30(8): 1461-1476.

LaLonde, R. J. (1995). The promise of public sectorsponsored training programs. Journal of Economic Perspectives, 9(2): 149-168

LaLonde, R. J. (2003). Employment and training programs. In Robert A. Moffitt (Ed.), Means-Tested Transfer Programs in the United States. Chicago, Illinois: University of Chicago Press.

Larsson, L. (2003). Evaluation of Swedish youth labor market programs. The Journal of Human Resources. XXXVIII(4): 891-927.

Lehrer, K., Mbiti, I., \& McCasland, J. (forthcoming). Ghana National Apprenticeship Program impact evaluation: Effort, incentives, and returns. Innovations for Poverty Action, Ghana. Retrieved from USAID website: http://www.usaid.gov/div/portfolio/ghana-nationalapprenticeship
Leuven, E., Oosterbeek, H., \& van der Klaauw, B. (2003). The effect of financial rewards on students' achievement: Evidence from a randomized experiment. Journal of the European Economic Association, 8(6): 1243-1265

Linn, P. L., Ferguson, J., \& Egart, K. (2004). Career exploration via cooperative education and lifespan occupational choice. Journal of Vocational Behavior, 65(3): 430-447.

Linnehan, F. (1996). Measuring of a career academy program from an employer's perspective. Educational Evaluation and Policy Analysis, 18(1): 73-89.

Lowry, A. E. (2007). Effects of online versus face-to-face professional development with a team- based learning community approach on teachers' application of a new instructional practice (Doctoral Dissertation). Baltimore: Johns Hopkins University.

Loyalka, P., Liu, C., Song, Y., Yi, H., Huang, X., Wei, J... Rozelle, S. (2013a). Can Information and counseling help students from poor rural areas go to high school? Evidence from China. Journal of Comparative Economics, 41 (4), 1012-1025.

Loyalka, P., Song, Y., Wie, J., Zhong, W., \& Rozelle, S. (2013b). Information, college decisions and financial aid: Evidence from a cluster-randomized trial in China. Economics of Education Review,36, 26-40.

Loyalka, P., Huang, X., Zhang, L., Wei, J., Yi, H., Song, Y... Rozelle, S. (2013c). The Impact of Vocational School on Human Capital Development in Developing Countries: Evidence from China (Working Paper 265). Rural Education Action Project.

Macdonald, I.S., Bullen, M., \& Kozak, R.A. (2010). Learner support requirement for online workplace training in the South African furniture industry. Journal of Asynchronous Learning Networks, 14(3), 49-59.

Maclean, R., Jagannathan, S., \& Sarvi, J. (Eds.). (2013). Skills Development for Inclusive and Sustainable Growth in Developing Asia-Pacific. In Technical and Vocational Education and Training: Issues, Concerns and Prospects, 19. Mandaluyong City: Asian Development Bank.

Maki, W. S., \& R. H. Maki. (2002). Multimedia comprehension skill predicts differential outcomes of Web-based and lecture courses. Journal of Experimental Psychology: Applied, 8(2): 85-98. 
Malamud, O., \& Pop-Eleches, C. (2010). General education versus vocational education: Evidence from an economy in transition. The Review of Economics and Statistics, 92(1): 43-60.

Martin, G., Massy, J., \& Clarke, T. (2003). When absorptive capacity meets institutions and (e)learners: adopting, diffusing and exploiting e-learning in organizations. International Journal of Training and Development, 7(4).

Martinez-Fernandez, C., \& Choi, K. (Eds.). (2012). Skills Development Pathways in Asia: Employment and Skills Strategies in Southeast Asia initiative (ESSSA). Paris, France: OECD.

Maxwell, N. (2001). Step to college: Moving from the high school career academy through the 4-year university. Evaluation Review, 25, 619-654.

Maxwell, N., \& Rubin, V. (2002). High school career academies and post-secondary outcomes. Economics of Education Review, 21 (2), 137-152.

McCain, M. L. (2009). Expanding access to adult education \& workforce skills through distance learning. New York, NY: Council for Advancement of Adult Literacy.

Mclntosh, S. (2007). A cost-benefit analysis of apprenticeships and other vocational qualifications (Research Report RR 834). Annesley, England: Department for Education and Skills.

McKay, E., \& Izard, J. (2012). Investigating online training in government agencies: designing adaptive webbased instructional programmes to reskill the workforce. International Journal of Business Research, 12(3): 69-83

McKay, E., \& Vilela, C. (2011). Corporate sector practice informs online workforce training for Australian government agencies: Towards effective educationallearning systems design. Australian Journal of Adult Learning, 51 (2): 302-328.

Medina, C., \& Núñez, J. (2005). The impact of public and private job training in Colombia. (Research Network Working Paper No. R-484). Washington, DC: InterAmerican Development Bank.

Mensch, B. S., Grant, M. J., Sebastian, M. P., Hewett, P. C., \& Huntington, D. (2004). The effect of a livelihoods intervention in an urban slum in India: do vocational counseling and training alter the attitudes and behavior of adolescent girls? (Working Paper No. 194). New York: The Population Council, Inc.
Mentzer, G. A., Cryan, J., \& Teclehaimanot, B. (2007). A comparison of face-to-face and Web-based classrooms. Journal of Technology and Teacher Education 15(2):23346.

Mo, D., Zhang, L., Yi, H., Luo, R., Rozelle, S., \& Brinton, C. (2013). School dropouts and conditional cash transfers: Evidence from a randomised controlled trial in rural China's junior high schools. Journal of Development Studies, 49(2): 190-207.

Moebs, S.A. (2007). A good mix in blended learning for small and medium-sized enterprises in particular from the IT and tourism industry (Masters Thesis). Dublin, Ireland: The National College of Ireland.

Moenjak, T., \& Worswick, C. (2003). Vocational education in Thailand: A study of choice and returns. Economics of Education Review, 22(1): 99-107.

Mohrenweiser, J., \& Backes-Gellner, U. (2010). Apprenticeship training, what for: Investment or substitution? International Journal of Manpower, 31 (5): 545-562.

Mohrenweiser, J., \& Zwick, T. (2009). Why do firms train apprentices? The net cost puzzle reconsidered. Labor Economics, 16(5): 631-637.

Moran, L., \& Rumble, G. (Eds.). (2004). Vocational education and training through open and distance learning. London, England: Routledge Falmer.

Mühlemann, S., Schweri, J., Winkelmann, R., \& Wolter, S. C. (2007). An empirical analysis of the decision to train apprentices. Labour: Review of Labour Economics and Industrial Relations, 21 (3): 419-441.

Mupinga, D., \& Busby, J. R. (2011). Online games and simulations as instructional strategies for vocational education and training. International Journal of Vocational Education and Training, 19(1): 77-87.

Nasr, K. J., Pennington, J., \& Andres, C. (2004). A study of students' assessment of cooperative education outcomes. Journal of Cooperative Education \& Internships, 38(1), 13-21.

Nguyen, H. Q., Donesky-Cuenco,Wolpin, D. S., Reinke, L. F. Benditt, J. O. Paul, S. M., \& Carrieri-Kohlman, V. (2008). Randomized controlled trial of an Internet-based versus face-to-face dyspnea self-management program for patients with chronic obstructive pulmonary disease: Pilot study. Journal of Medical Internet Research 10(2). 
Nguyen, T. (2008). Information, Role models and perceived returns to education: Experimental evidence from Madagascar (Job Market Paper). Cambridge: Massachusetts Institute of Technology.

Nivorozhkin, A., \& Nivorozhkin, E. (2007). Do government sponsored vocational training programmes help the unemployed find jobs? Evidence from Russia. Applied Economics Letters, 14, 5-10.

Ocker, R. J., \& G. J. Yaverbaum. 1999. Asynchronous computer-mediated communication versus face-to-face collaboration: Results on student learning, quality and satisfaction. Group Decision and Negotiation 8(5), $427-$ 40.

O'Dwyer, L. M., Carey, R., \& Kleiman, G. 2007. A study of the effectiveness of the Louisiana Algebra I online course. Journal of Research on Technology in Education $39(3), 289-306$.

Orbeta, A. C., Jr., \& Abrigo, M. R. (2013). An assessment of TESDA scholarship programs (Research Paper). Makati City: Philippine Institute for Development Studies.

Oreopoulos, P., \& Dunn, R. (2013). Information and college access: Evidence from a randomized field experiment. Journal of Economics, 115(1): 3-26.

Origo, F., \& Patrizio, M. (2013). Apprenticeships, traineeships and labour market outcomes: A cross country regression analysis. In The effectiveness and costs-benefits of apprenticeships: Results of the quantitative analysis (pp. 8-17). European Commission, Directorate-General for Employment, Social Affairs and Inclusion, European Union.

Orr, M.T., Bailey, T., Hughes, K., Karp, M. M., \& Keinzl, G. S. (2004). The National Academy Foundation's career academies: Shaping postsecondary transitions (IEE Working Paper, No. 17). New York, NY: Institute for Education and Economy.

Padalino, Y., \& Peres, H. H. C. (2007). E-learning: A comparative study for knowledge apprehension among nurses. Revista Latino-Americana de Enfermagem, 15(3): 397-403.

Page, L. (2012). Understanding the impact of career academy attendance: An application of the principal stratification framework for causal effects accounting for partial compliance. Evaluation Review, 36(2): 99-132.
Pan, W., Sun, L.Y., \& Chow, I.H.S. (2011). The impact of supervisory mentoring on personal learning and career outcomes: The dual moderating effect of self-efficacy. Journal of Vocational Behavior, 78(2): 264-273.

Parey, M. (2009), Vocational schooling versus apprenticeship training. Evidence from vacancy data, Unpublished manuscript, University of Essex and Institute for Fiscal Studies.

Park, S., Sim, H., \& Roh, H. (2010). The analysis of effectiveness on 'transfer' through e-learning courses in industry and technology. British Journal of Educational Technology, 41 (6): E132-E134.

Patrinos, H., \& Ariasingam, D. L. (1997). Decentralization of education demand-side financing. Washington, D.C.: the World Bank.

Paulsen, M. F. (2009). Successful e-learning in small and medium-sized enterprises. Retrieved from European Journal of Open, Distance and E-Learning: http://www. eurodl.org/materials/contrib/2009/Morten_Paulsen.pdf

Perdrix, S., Stauffer, S., Masdonati, J., Massoudi, K., \& Rossier, J. (2012). Effectiveness of career counseling: A one-year follow-up. Journal of Vocational Behavior, $80(2): 565-578$.

Philip, O., \& Dunn, R. (2013). Information and college access: Evidence from a randomized field experiment. Scandinavian Journal of Economics 115(1): 3-26.

Phoewhawn, R. (2012). From the classroom to the workplace: a cooperative education stratagem for student transitioning skills. International Journal of Innovation and Learning, 12(2): 122-141.

Raaum, O., \& Torp, H. (2002). Labour market training in Norway effect on earnings. Labour Economics, 9(2): 207-247

Raelin, S., Bailey, M. B., Hamann, J., Pendleton, L. K., Raelin, J. D., Rilsberge, L. R., \& Whitman, D. (2011). The effect of cooperative education on change in selfefficacy among undergraduate students: Introducing work self-efficacy. Journal of Cooperative Education \& Internships, 45(2): 17-35.

Ragins, B.R., Cotton, J.L., \& Miller, J.S. (2000). Marginal mentoring: the effects of type of mentor, quality of relationship, and program design on work and career attitudes. Academy of Management Journal, 43(6), 1177-1194. 
Rauner, F., \& Rupert, M. (Eds.). (2009). Handbook of Technical and Vocational Education and Training Research. Dordtrecht, Netherlands: Springer Science+Business Media.

Rauner, F., Heinemann, L., Maurer, A., \& Haasler, B. (2013). Competence development and assessment in TVET (COMET): Theoretical framework and empirical results. Series: technical and vocational education and training: Issues, concerns and prospects (Vol. 16). Dordtrecht, Netherlands: Springer Science+Business Media.

Ravallion, M., \& Wodon, Q. (2000). Does child labor displace schooling? Evidence on behavioral responses to an enrollment subsidy in Bangladesh. Economic Journal, 110(462): 158-176.

Raynor, J., \& Wesson, K. (2006). The girls' stipend program in Bangladesh. Journal of Education for International Development, 2(2): 1-9.

Reenen, J. V. (2004). Active labor market policies and the British New Deal for the young unemployed in context. In D. Card, R. Blundell, \& R.B. Freeman (Eds.), Seeking a premier economy: The economic effects of British economic reforms, 1980-2000 (461-496). Chicago, IL: University of Chicago Press.

Reller, D. J. (1984). The Peninsula Academies: Final technical evaluation report. Palo Alto, CA: The American Institutes for Research.

Reller, D. J. (1985). The Peninsula Academies, interim evaluation report, 1984-85 school year. Palo Alto, CA: American Institutes for Research.

Reller, D. J. (1987). A longitudinal study of the graduates of the Peninsula Academies, final report. Palo Alto, CA: American Institutes for Research.

Rezin, A. A., \& McCaslin, N. L. (2001). Comparing the impact of traditional and cooperative apprenticeship program on graduates' industry success (Working Paper). London: International Business Research Conference.

Richard, E. D., Walter, R. A., \& Yode, E. P. (2013). The effect of capstone cooperative education experiences, and related factors, on career and technical education secondary student summative assessment scores. Career \& Technical Education Research, 38(1): 19-37.
Richardson, K., \& van den Berg, G. J. (2008). Duration dependence versus unobserved heterogeneity in treatment effects: Swedish labor market training and the transition rate to employment (Working Paper No.7). Uppsala: The Institute for Labour Market Policy Evaluation (IFAU).

Rodriguez-Planas, N. (2007). What works best for getting the unemployed back to work: Employment services or small-business assistance programmes? Evidence from Romania (Working Paper No. 3051). Retrieved from Institute for the Study of Labor Discussion website: http://ftp.iza.org/dp3051.pdf

Rojewski, J. W., Lee, H., \& Gemici, S. (2010). Using propensity score matching to determine the efficacy of secondary career academies in raising educational aspirations. Career \& Technical Education Research, 35(1): 3-27.

Rosholm, M., Nielsen, H. S., \& A. Dabalen, A. (2007). Evaluation of training in African enterprises. Journal of Development Economics, 84(1): 310-329.

Rozelle, S., Park, A., Wan, S., Zhang, L., Rong, W., Song, Y., ... Shi, Y. (2015). Investment in vocational vs. general schooling: Evaluating China's expansion of vocational education and laying the foundation of further vocational education evaluation (S.3ie Grantee Final Report). New Delhi, India: International Initiative for Impact Evaluation (3ie)

Ryan, C. (2013). Student income support and education and training participation in Australia (Research Report 62). Adelaide, Australia: Longitudinal Surveys of Australian Youth Research, NCVER.

Saavedra, J., \& Garcia, S. (2012). Impacts of conditional cash transfer programs on educational outcomes in developing countries: A meta-analysis (Working Paper WE-921-1). Retrieved from Rand Corporation website: https://www.rand.org/content/ dam/rand/pubs/working_papers/2012/RAND_WR921 1.pdf

Salleh, B. M., Esa, A., Selamat, A., Othman, H., Sulaiman, A., \& Suhaimy, K.A. (2010). Computermediated communication as a tool for improving the English language among adult learners in TVET programme. Journal of Technical Education and Training (JTET), 2(1): 31-43.

Schilling, K., Wiecha, J., Polineni, D., \& Khalil, S. (2006). An interactive Web-based curriculum on evidencebased medicine: Design and effectiveness. Family Medicine, 38(2): 126-32. 
Schochet, P. Z., Burghardt, J., \& McConnell, S. (2006). National Job Corps study and longer-term follow- up study: Impact and benefit-cost findings using survey and summary earnings records data. Princeton, N.J.: Mathematica Policy Research, Inc.

Schoenfeld-Tacher, R., McConnell, S., \& Graham, M. (2001). Do no harm: A comparison of the effects of online vs. traditional delivery media on a science course. Journal of Science Education and Technology 10(3): 257-265.

Seibert, S. (1999). The effectiveness of facilitated mentoring: A longitudinal quasi-experiment. Journal of Vocational Behavior, 54(3): 483-502.

Sexton, J. S., Raven, M. R., \& Newman, M. E. (2002). A comparison of traditional and World Wide Web methodologies, computer anxiety, and higher order thinking skills in the in-service training of Mississippi 4-H extension agents. Journal of Agricultural Education, 43(3): $25-36$

Sitzmann, T., Kraiger, K., Stewart, D., \& Wisher, D. (2006). The comparative effectiveness of Web-based and classroom instruction: A meta-analysis. Personnel Psychology, 59(3): 623-664.

Spielhofer, T., Nelson, J., O'Donnell, L., \& Sims, D. (2006). The role of training allowances in incentivising the behaviour of young people and employers (Research Report RR756). Annesley, England: Department for Education and Skills.

Stern, D., Dayton, C., Paik, I.W., \& Weisberg, A., (1989). Benefits and costs of dropout prevention in a high school program combining academic and vocational education: Third year results from replications of the California peninsula academies. Educational Evaluation and Policy Analysis, 11 (4): 405-416.

Stern, D., Dayton, C., \& Raby, M. (2010). A proven strategy to prepare high school students for college and careers. Berkeley, CA: Career Academy Support Network (CASN), University of California.

Stern, D., Finkelstein, N., Urquiola, M., \& Cagampang, H. (1997). What difference does it make if school and work are connected? Evidence on co-operative education in the United States? Economics of Education, 16(3): 213-229.

Stoeger, H., Duan, X., Schirner, S., Greindl, T., \& Ziegler, A. (2013). The effectiveness of a one-year online mentoring program for girls in STEM. Computers \& Education, 69(59): 408-418

Styron, R., \& Peasant E. (2010). Improving student achievement: Can ninth grade academies make a difference? International Journal of Education Policy \& Leadership, 5(3): 1-9.

Su, Z., \& Zeng, X. (2009). China's national vocational qualifications and their impact on technical workers' skill level, job performance and earnings: Evidence from six enterprises in the manufacturing industry. Paper presented at 1st CIER/IZA Annual Workshop: Research in Labor Economics, Beijing, China. Retrieved from Institute of the Study of Labor (IZA) website: http://www.iza.org/conference_files/ LabEco2009/su_z5566.pdf

Sung, J. (2010). Vocational education and training and employer engagement: An industry-led sectoral system in the Netherlands. International Journal of Training and Development, 14(1): 16-31.

The World Bank. (2013). Turkey: Evaluating the impact of Iskur's vocational training program. (Report No: 82306 - TR). Retrieved from the World Bank website: http://documents.worldbank.org/curated/ en/2013/08/19151577/turkey-evaluating-impact-iskursvocational-training-programs-vol-1-2-final-report

Torchio, N. (2013). A Review of Existing Evaluation Studies on Apprenticeship and Traineeship Schemes. In The effectiveness and costs-benefits of apprenticeships: Results of the quantitative analysis (pp. 8-17). European Commission, Directorate-General for Employment, Social Affairs and Inclusion, European Union.

Tripney, J., Hombrados, J. G., Newman, M., Hovish, K., Brown, C., Steinka-Fry, K.T., \& Wilkey, E. (2013). Post-basic technical and vocational education and training (TVET) interventions to improve employability and employment of TVET graduates in low- and middle-income countries: A systematic review. The Campbell Collaboration Library of Systematic Reviews, 9.

UNESCO. (2013). Report for the UNESCO-UNEVOC online conference: ICT's for TVET. Bonn: UNESCOUNEVOC International Centre for Technical and Vocational Education and Training.

UNESCO Institute for Information Technologies in Education. (2012). Special report on the activities implemented within the joint IFESCCO/UNESCO IITE project "Promotion of the use of ICTS in TVET in CIS 
countries". Moscow: UNESCO Institute for Information Technologies in Education.

UNESCO. (2011). UNESCO National Education Support Strategy (UNESS) Thailand. UNESCO Office Bangkok and Regional Bureau for Education in Asia and the Pacific, PROAP.

UNESCO. (n.d.). Higher education and technical and vocational education and training. Retrieved from http://www.unescobkk.org/education/resources/ resources/education-system-profiles/thailand/highertvet/

United States Department of Education, Office of Planning, Evaluation, and Policy Development. (2009). Evaluation of evidence-based practices in online learning: A meta-analysis and review of online learning studies. Washington, DC.

Usher, A., \& Kober, N. (2012). Can money or other rewards motivate students? Washington, DC:

Center on Education Policy, George Washington University Graduate School of Education and Human Development.

Visher, M. G., Altuna, J. N., \& Stefan, S. (2013). Making it happen: How career academies can build college and career exploration programs. New York, NY: MDRC.

Walsh, K., Kotzeva, M., Dölle, E., \& Dorenbos. R. (2001). Evaluation of the net impact of active labour market programmes in Bulgaria. NEl Labour and Education, Summary, EB5213 DOL/AL.

Walters, D., \& Zarifa, D. (2008). Earnings and employment outcomes for male and female postsecondary graduates of coop and non-coop programmes. Journal of Vocational Education and Training, 60(4): 377-399.

Watts, A. G. (2009). The relationship of career guidance to VET. Paris, France: OECD.

Weise, M. R., \& Christensen, C. M. (2014). Hire education: Mastery, modularization, and the workforce revolution. San Mateo, CA: Clayton Christensen Institute for Disruptive Innovation.

Werwatz, A. (2002). Occupational mobility after apprenticeship-How effective is the German apprenticeship system? Applied Economics Quarterly, 48(3-4): 279-303.

Wessels, W., \& Pumphrey, G. (1995). The effects of cooperative education on job search time, quality of job placement and advancement. Journal of Cooperative Education, 31 (1): 42-52.
Wessels, W., \& Pumphrey, G. (1996). The impact of cooperative education on wages. Journal of Cooperative Education, 32(1): 36-51.

Westergaard-Nielsen, N., \& Rasmussen, A. R., (2000). The impact of subsidies on the number of new apprentices. Research in Labor Economics, 18, 359-375.

Wolf, A. (2011). Review of vocational education: The Wolf Report. Independent report for the Department for Education and Department for Business, Innovation \& Skills, Government of the United Kingdom. Retrieved from UK Government website: https://www.gov.uk/ government/uploads/system/uploads/attachment_ data/file/180504/DFE-00031-2011.pdf

Wolter, S.C., Mühlemann, S., \& Schweri, J. (2006). Why some firms train apprentices and many others not. German Economic Review, 7(3): 249-264.

Wongmonta, S. (2012). Three essays on the economics of education in Thailand (Doctoral dissertation). Retrieved from University of Minnesota: http://conservancy.umn. edu/handle/135836.

Woottipong, K. (2013). The development of webbased instruction in English paragraph writing for undergraduate university students. Malaysian Journal of ELT Research, 9(2): 49-81.

Wu, Y. L., Tsai, Y. L., \& Chen, C. W. (2014). Examining the experiences of career guidance, vocational selfconcept and self-perceived employability among science education majors in Taiwan. Journal of Baltic Science Education, 13(2): 182-190.

Xu, D., \& Jaggars, S. S. (2013). The impact of online learning on students' course outcomes: Evidence from a large community and technical college system. Economics of Education Review 37: 46-57.

Zwick, T. (2007) Apprenticeship training in Germany Investment or productivity driven? (Discussion Papers, n. 07-023). Center for European Economic Research (ZEW). 


\section{APPENDIX A. Occupational Information Systems}

Year

O*NET

\section{Asia Power}

National Careers Service

Northern Ireland Direct

International Centre for

Guidance Studies

National Careers Council

European Lifelong Guidance

Policy Network

OECD

Careers New Zealand

Korean Research Institute for Vocational Education \& Teaching

Asia Pacific Career Development Association

Canadian Career Development Foundation

International Association for Educational and Vocational Guidance

Job Guide

Australian Apprenticeships

National Centre for Vocational Education Research

Australian Government Dept. of Education and Training

Job Services Australia

\section{Study title/Author}

http://www.onetcenter.org/overview.html

http://asiapower.in

https://nationalcareersservice.direct.gov.uk/Pages/Home.aspx

http://www.nidirect.gov.uk/careers

http://www.derby.ac.uk/research/icegs/

https://www.gov.uk/government/groups/the-national-careerscouncil

http://www.elgpn.eu

http://www.oecd.org/education/innovation-education/ careerguidancepolicyreviewhomepage.htm

http://www.careers.govt.nz

http://eng.krivet.re.kr/eu/index.jsp

http://www.asiapacificcda.org

http://www.ccdf.ca/ccdf/

http://www.iaevg.org/iaevg/index.cfm?lang=2

http://www.jobguide.education.gov.au

http://www.australianapprenticeships.gov.au

http://www.ncver.edu.au

http://training.gov.au

http://employment.gov.au/job-services-australia-jsa
EU

New

Zealand

Korea

Asia

Canada

$N / A$

Australia

Australia

Summary of indings

USA

Asia

UK

Ireland

UK

UK

Australia

Australia

Australia 


\section{APPENDIX B. Policy Guidance Literature}

In addition to the efficacy literature, which makes up the bulk of this literature review, a number of policy-relevant reports, manuals, and books have been identified through our systematic searches. Here, we provide a brief description of eight of the most recent, relevant, and high-quality "policy guidance papers" as tools that could be used by policymakers moving forward.

\section{Active labor market policies by topic:}

- The OECD's "Learning for Jobs" (Field et al., 2010) is a synthesis report of reviews of vocational education and training and provides policy guidance for practitioners on active labor market strategies (vocational education, career guidance, workplace learning, tools to support the system, etc.). The guidance is directed at OECD countries but may have implications for other regions.

- From the Asian Development Bank (Maclean et al., 2013), the book, Skills Development for Inclusive and Sustainable Growth in Developing Asia-Pacific, is a collection of views and insights from policymakers, practitioners, and leading experts on skills development for "inclusive and sustainable growth." The book examines current strategies in TVET in the Asia and Pacific region, with special attention to the "link between technical and vocational education and training and the imperatives of greening economies." The authors also propose an international framework (across the Asia and Pacific region) for policymakers to consider moving forward.

- The International Handbook of Career Guidance (Athanasou \& Esbroeck, 2008) is a reference book which provides a comprehensive view of career guidance policies internationally, with particular emphasis on vocational guidance. The handbook covers the following topics: educational and vocational guidance in a social context; theoretical foundations; educational and vocational guidance in practice; specific target groups; testing and assessment; and evaluation.

- The Review of Vocational Education: The Wolfe Report (Wolfe, 2011), focuses on vocational education for 14- to 19 -year-olds in England, and summarizes a wealth of qualitative evidence that sheds light on ways to promote the successful progression of this population into the labor market, as well as higher education and training. The report provides policy recommendations that take special account of England's current financial situation.

\section{Active labor market policies by country (case studies):}

- The OECD's "Skills Development Pathways in Asia" (Maclean, Jagannathan, \& Sarvi, 2012) is a report that provides a series of case studies across 15 Asian nations, which detail the strategies for skills development in each country. These case studies are summaries of discussions held at the annual meetings of the Employment and Skills Strategies in Southeast Asia initiative (ESSSA) in Tokyo (2010) and Shanghai (2011) in relation to policies and programs for skills development approaches in Asian countries. Countries covered include: Australia, Cambodia, China, Hong Kong, China, India, Japan, Korea, Malaysia, Mongolia, Nepal, Pakistan, the Philippines, Singapore, Thailand, and Vietnam.

\section{Guidance on the use of ICTs in technical and vocational training:}

- UNESCO's (Chinien, 2003) report on "The use of ICTs in Technical and Vocational Education and Training," reviews the use of ICTs for administrative purposes; communication, teaching and learning; curriculum development and assessment; career education and guidance; labor market information; job placement; and systems control. Through survey and case study means, the authors (1) provide an overview of the various types of programs found under each of the above topics and (2) provide case study evidence of the ways in which countries are using ICTs for TVET.

- UNESCO's "ICT Application in Technical and Vocational Education and Training: Specialized training course" (Chinien, 2005), provides participants with the opportunity to "acquire and develop the knowledge and practical skills necessary to establish, manage, and appraise ICT-mediated teaching and learning in TVET." 
This course was designed specifically for policymakers and managers/administrators of TVET-related programs and trainings, and includes three models: Implementation of ICT-mediated teaching and learning in TVET; ICTmediated teaching in TVET; and ICT-mediated learning in TVET. Each unit of the three-module course includes instructional objectives, relevant training materials for each objective, and corresponding application exercises.

\section{Conducting research on TVET policies:}

- The Handbook of Technical and Vocational Education and Training Research from UNEVOC focuses on the research methods used to evaluate labor market strategies and vocational training in particular (Rauner \& Rupert, 2009). The authors provide a review of the methods, including a sample of case studies used to illustrate different approaches to TVET research. The research methods presented include interview-based and observational methods, as well as experimental and process evaluations. This may be a useful resource in setting up an evaluation of the Thai government's new labor market policies.

- $\quad$ The book, Competence Development and Assessment in TVET (COMET): Theoretical Framework and Empirical Results, also from UNEVOC, uses a case study to test a methodology for measuring vocational competence, which could potentially be employed internationally. The authors demonstrate that the "methodology can be applied to designing and evaluating vocational education and training processes," making the material relevant to VET teachers and trainers as well as academics. 


\section{APPENDIX C. Literature Search Strategy}

The literature search strategy is described below for each topic:

\section{Vocational Education}

Fifteen studies of the impact of vocational education on youth were identified for inclusion in this synthesis. These studies described were identified through (1) a review of a recently published meta-analysis on vocational education and training in low and middle income countries; (2) citation crawling of metaanalysis and highly cited studies; (3) a search of the Impact Evaluation (3ie) database and the Youth Employment Inventory; and (4) primary searches of the following databases from 06/01/2014-08/15/2014: Education Research Complete, Business Source Complete, ERIC, Education Full Text, Social Sciences Full Text, and EconLit with Full Text, as well as Google Scholar. Search terms included: "workforce training," "vocational programs," "vocational education," "vocational school," "vocational training," "trade school," "school-towork," "school-to-career," "VET," "TVET," "tech prep," "active labor market policies," "active labor market programs," "STEM technicians," and "dual vocational."

\section{Apprenticeships}

Twenty-seven efficacy studies regarding the impact of apprenticeships on youth outcomes were identified for inclusion in this synthesis. In addition, one systematic review examining the impact of apprenticeships on life outcomes (in Europe) was also included in this review. These studies described were identified in two main ways: (1) through citation crawling of the meta-analyses and highly cited studies, including a recent systematic review (Torchio, 2013) and (2) through primary searches of the following databases from 08/01/2014-08/15/2014: Education Research Complete, Business Source Complete, ERIC, Education Full Text, Social Sciences Full Text, and EconLit with Full Text, as well as Google Scholar. Search terms included: "apprenticeship" OR "active labor market policies" OR "active labor market programs" OR "workplace learning" OR "workforce development" OR "career internship" OR "learning-by-doing" OR "On-the-job training."

\section{Cooperative Education}

Twenty-three studies regarding the impact of cooperative education were identified for inclusion in this synthesis. Based on a systematic review examining cooperative education in EBSCO host with Education Research Complete, Business Source Complete, ERIC, Education Full Text, Social Sciences Full Text, and Econ Lit with Full Text, covering the years 2000 2014, the most relevant impact studies were identified. Upon the reading of these studies, influential studies prior to 2000 were also added to the analysis.

Career Academies

Seventeen studies are included in the analysis. The search process for studies examining the impact of career academies on students included:

a. A word search with "Career Academies" and "Career Academies and Education work relationship" to find literature in the ERIC database published between 2000-2014 (728 hits). Among them, 385 scholarly articles and 50 evaluative reports were identified as potentially relevant. The abstract of each publication was then reviewed to determine the rigor of its research design. Seventeen publications were selected for the literature review.

b. A search of education databases and labor economy databases via EBSCOhost. Five relevant databases were included for the search: EconLit with Full Text; Education Full Text (H.W. Wilson); Education Research Complete; ERIC; and PsycINFO. The same search terms were used: "Career Academies" or "Career Academies and Education work relationship" within the abstract, published between 2000-2014. Two 
hundred seventeen articles were identified, and the abstract of each one was reviewed to identify its rigor. Sixteen additional publications were added to the literature review.

c. A search of the website of Association for Career and Technical Education, which includes the clearing house on Career Academies and Small Learning Communities. Two additional publications that discuss the CTE framework were added to the pool.

d. In addition to the literature found through systematic database research, three studies conducted prior to 2000 were identified as important from examining study references and were included (Stern, et al., 1989; Linnehan, 1996; Kimpel, 1997).

e. In all, 39 articles and evaluative reports were reviewed for this section of the review, and findings from the most relevant and rigorous 17 are included in the analysis.

\section{Workforce Training Through E-learning}

Twenty efficacy studies in the field of e-learning for post-secondary young adults/adults were identified for inclusion. In addition, two meta-analyses and 30 high-quality, non-experimental case studies, journal articles, and policy reports were included.

These studies were identified through a systematic search of the literature, including searches of the following databases conducted from 01/10/2014-01/17/2014: Education Research Complete, Business Source Complete, ERIC, Education Full Text, Social Sciences Full Text, and EconLit with Full Text. The search terms used for this portion of the literature review were as follows (concatenated):

a. E-learning related: "online" OR "on-line" OR "e-learning" OR "distance learning" OR "distance education" OR "ICT" OR "IT" OR "information technology" OR "computer assisted" OR "computer-assisted" OR "computer based training" OR "computer-based instruction" OR "virtual" OR "computer-mediated" OR "web-based" OR "electronic learning" OR "technology-enabled" OR "communications technology" OR "ICT for TVET"or "ICT for VET"

b. Education/Training related: "education" OR "learning" OR "training" OR "job training" OR "instruction" OR "program" OR "skill*" OR "degree" OR "certificate" OR "credential" OR "vocation*" OR "School" OR "STEM"

c. Vocational/workforce related: "vocational education" "workforce development" OR "work" OR "workforce" OR "job" OR "industry" OR "industries" OR "on-the-job" OR "enterprise*" OR "economy" OR "profession" OR "manpower" OR "skill training" OR "human resource development"

In addition, citation crawling of the references in the studies identified was used, and searches of the World Bank, UNESCO, ILO, and OECD websites were also conducted.

\section{Information Interventions}

Six impact evaluations dealing with the effects of information provision on educational choices were included in this synthesis, as well as one descriptive study of student perceptions of educational opportunities (seven studies in total). These studies were identified in two main ways: (1) through primary searches of academic databases: Education Research Complete, Business Source Complete, ERIC, Education Full Text, Social Sciences Full Text, and EconLit with Full Text and searches conducted from 08/01/2014-08/18/2014 and (2) through "citation crawling" of the references listed in the studies found below. Search terms for these informational studies included the terms: "educational information," OR "information interventions," OR "educational services," OR "educational guidance," OR "returns to education," OR "student perceptions and education," OR "student expectations and education." 


\section{Career Counseling}

Eighteen efficacy studies regarding the impact of career counseling on youth and current employees and professionals were identified for inclusion in this synthesis. Studies detailed below were identified in three ways: (1) through a recently published meta-analysis on career counseling and mentoring, (2) through "citation crawling" of the studies found in the references below, and (3) through primary searches of academic databases (including EBSCOhost, ERIC and ProQuest), journals, and Google Scholar. Searches were conducted from 7/24/2014 8/14/2014. The key search terms include: "career," "counseling," "guidance," "mentoring," "math," "science," "STEM," "effect," "evaluation," "impact," "earning," "income," and "salary."

\section{Access to Industry Credentials}

There was no efficacy literature that looked explicitly at the impact of access to industry credentials on student outcomes. A search of the literature was conducted, including searches of the following databases: Education Research Complete, Business Source Complete, ERIC, Education Full Text, Social Sciences Full Text, and EconLit with Full Text. Instead example s of current credentialing programs and systems (found through articles, reports, and websites) were located through searches on Google. Key search terms included: "certification system," "credential system," "training system," "industry," "government," "STEM," "technical," and "vocational."

\section{Monetary Incentives for Students}

Preliminary research findings using financial incentives concepts paired with key words such as "non-formal education," "science and technology," "adult education," and "Asia" yielded few results. After exhaustive attempts using different key word combinations to find high-quality literature specific to this, it became apparent that literature on financial incentives within the non-formal STEM sector is non-existent.

The next phase of the search used Proquest, Ebscohost, and ERIC searches and included key word combinations with vocational education on one end and incentive concepts on the other. Incentive concept key words used to search the databases included words such as "incentives," "pay students," "tuition waiver," "financial aid," "training subsidy," "loans," "disincentives," "vouchers," "demand-side financing," and "conditional cash transfers." Due to limited results in preliminary research, the years searched were left open ended, but a parameter set for inclusion into the review included post 1997 studies.

Finally, citation tracking, Google, and specific organization searches were used to extract papers more relevant to the focus of this review. Specially, the search sought to find impact evaluations of incentive employing projects. Research published, overseen, or assisted by the World Bank, the OECD, and the Asian Development Bank was examined. The papers included in this review maintained standards of a sound methodology, with preference given to studies utilizing experimental or quasi-experimental design. In totality, these search terms and strategies yielded a total of 28 studies included in this synthesis.

Please note that throughout the course of this literature review non-evaluative literature was also uncovered and entered into a separate spreadsheet with the names of organizations and programs that use incentives to assist in learning goals. Details on what the incentive is and to whom it is given are provided.

\section{Incentives for Industries}

The first phase of the search for literature relevant to industry incentives (incentives for employers to provide on the job training or TVET), included search terms and synonyms of terms such as "employer benefits," "on the job training," "training stipend," and "subsidized training." The results did not yield high quality papers 
relevant to the goal of this paper, however, the search overlapped with findings on industry-recognized credentials as incentives.

The next phase of the search, searching within the framework of active labor market policy, led to more relevant and high-quality literature. Examples of search terms in this phase include "Asia," "active labor market policy," "wage subsidies," "employer tax incentive," and "tax credit." Databases searched include Ebscohost, ERIC, and Proquest. The Google search engine was also used to retrieve information from international organizations. The years were left open-ended to offer leads on expert authors and institutions regardless of year.

Of a total of fifteen papers found, only eight have been included into this synthesis. Parameters for inclusion and exclusion are detailed below:

a. Peer reviewed journals or academic institution publications received priority for inclusion.

b. Papers published by institutions whose findings seemed tied to the interests of the research client or subjects were excluded.

c. Policy and working papers that established sound findings relevant to the subject were included.

d. Papers that discussed employer incentives within an economic framework that did not provide direct evidence on the impact of incentives on motivating employers were included.

e. Papers published through institutions such as the Bonn-based Institute for the Study of Labor, the World Bank, and the OECD were included. 